\title{
LA JUSTICIA DISTRIBUTIVA GLOBAL: DEL IGUALITARISMO DE LA SUERTE AL CONSTRUCTIVISMO POLÍTICO *
}

\author{
Federico Arcos Ramírez \\ Universidad de Almería
}

RESUMEN. La interpretación más fuerte y polémica de la tesis del carácter institucional en lugar de moral del concepto de justicia distributiva, que ha recibido la denominación de concepción dependiente de la práctica, considera que las instituciones políticas juegan un papel decisivo no sólo de cara a la implementación de las exigencias de ésta, o a la determinación de los criterios distributivos para cada reparto, sino también a la formulación de los primeros principios. Esta concepción de la justicia ofrece una de las razones más poderosas para desacreditar la que, al menos para la primera generación de cosmopolitas modernos, constituyó el fundamento más habitual para tales deberes: el igualitarismo de la suerte. Este trabajo examina las claves desde las que podría construirse una justicia distributiva global a partir de la corrección o moderación a un doble nivel de la concepción dependiente de la práctica. En primer lugar, apuntando a la necesidad de combinar adecuadamente elementos independientes (racionales, morales o ideales) y dependientes de cara a evitar vaciar a la teoría de la justicia de su componente crítico y, sobre todo y, en segundo lugar, ampliando, con el auxilio de la noción de justicia de trasfondo y de la concepción sistémica de la coacción, el tipo de prácticas que generan demandas morales de la particularidad y exigencia característica de la justicia distributiva.

Palabras clave: justicia distributiva, igualitarismo de la suerte, cosmopolitismo, concepción de la justicia dependiente de la práctica, justicia de trasfondo, concepción sistémica de la coacción.

ABSTRACT. The strongest and polemic interpretation of the thesis of the institutional character instead of moral of the concept of distributive justice, which has received the denomination of conception practice dependent, considers that the political institutions play a decisive face role not only to the implementation of the requirements of this one or to the determination of the distributive criteria for every share-out, but also to the formulation of the first principles. This conception of the justice offers one of the most powerful reasons to discredit the one that, at least for the first generation of modern cosmopolitans, constituted the most habitual foundation for such duties: the luck egalitarism. This work examines the keys from the one that a local distributive justice might construct itself from the correction or moderation of the conception dependent on the practice at a double level. First of all, pointing at the need to combine appropriately independent elements (rational, moral or ideal) and dependents in order to avoid to empty to the theory of the justice of its critical component and, especially and secondly, extending, with the help of the notion of background justice and of the systemic conception of the coercion, the type of practices that generate moral demands of the peculiarity and demand typical of the distributive justice.

Keywords: distributive justice, luck egalitarism, cosmopolitanism, conception of justice practice-dependent, background justice, systemic conception of coercion.

* Fecha de recepción: 5 de julio de 2012. Fecha de aceptación: 15 de noviembre de 2012.

Este trabajo se enmarca en el proyecto de investigación de excelencia SEJ-6849, «Inmigración y Justicia Global» financiado por la Consejería de Economía, Innovación y Ciencia de la Junta de Andalucía. 


\section{INTRODUCCIÓN: REPENSAR LA JUSTICIA EN UN MUNDO GLOBALIZADO}

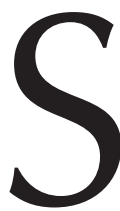

e ha convertido en un auténtico tópico de la filosofía política y social contemporánea que vivir en un mundo cada vez más interconectado e interdependiente, que el conformar una sociedad ininterrumpida ${ }^{1}$, impone el abandono de los viejos mapas y la elaboración de una nueva cartografía que nos permita atravesar los territorios del mundo globalizado ${ }^{2}$. Como resultado de la eclosión de las nuevas tecnologías o la dinámica expansiva de la producción y el comercio, entre otros, desde hace casi tres décadas las comunidades políticas han dejado de constituir el espacio natural o privilegiado del movimiento de las personas, los bienes, los servicios, la información, las manifestaciones culturales, etc., para dar paso a un mundo en el que todos estos procesos franquean continuamente las fronteras ${ }^{3}$. Sin perder de vista que quienes más reclaman la desnacionalización de la producción y el comercio estarían promoviendo muchas veces una renacionalización del discurso político ${ }^{4}$, la impresión dominante es que, en la sociedad mundial, resulta cada vez más difícil continuar hablando de la economía, la soberanía política o la cultura como realidades exclusivas o predominantemente nacionales o estatales.

¿Ocurre algo similar con la idea de la justicia? ¿Está la globalización, tal y como señala FRAZER, cambiando nuestra forma de discutir sobre ella? ${ }^{5}$. ¿Tienen los cambios señalados calado suficiente como para poner en cuestión el carácter estatal (intranacional e internacional) de la justicia o, como señala L. HiERRO, continúa el sistema de Estados cerrando al nivel del Estado-nación el ámbito de definición de los iguales? ${ }^{6}$. No hay duda de que los cambios provocados por la globalización imponen una revisión de algunos conceptos políticos empleados desde la modernidad. Sin embargo, ¿poseen también el suficiente calado como para poder hablar de una justicia global? Son muchos los que vienen señalando la conveniencia de servirnos de esta expresión para poner en consonancia la teoría con la realidad y, de paso, enfrentarnos mejor a los desafíos éticos que trae consigo un mundo cada vez más interconectado ${ }^{7}$. Empero, no conviene perder de vista el hecho de que, como proclama breve pero contundentemente NAGEL al comienzo de sus reflexiones sobre este problema, el principal desencadenante del interés por la justicia global es que «no vivimos en un mundo justo» ${ }^{8}$. Estamos, pues, ante una noción en la que confluyen las denuncias en torno a los riesgos y peligros (nucleares, medioambientales, terroristas, financieros, etc.) y las injusticias tan manifiestas que asolan nuestro mundo, en particular, las enormes desigualdades sociales y económicas entre individuos que viven en regiones distintas del planeta. Na-

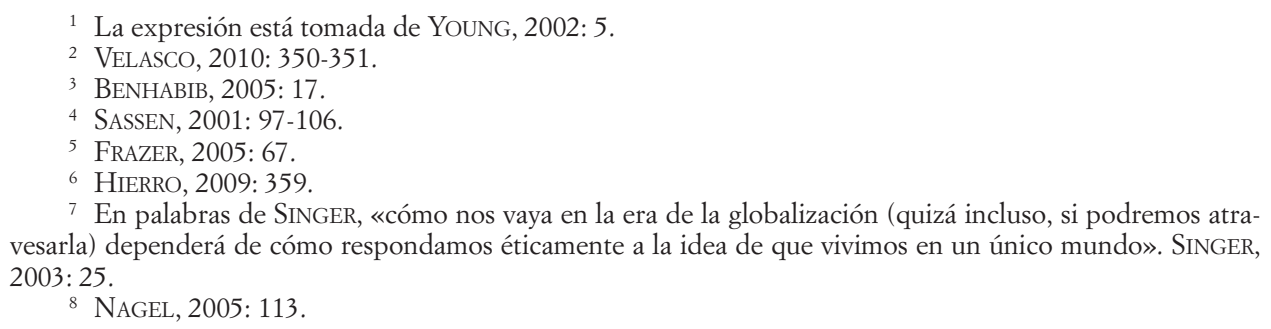

7 En palabras de SINGER, «cómo nos vaya en la era de la globalización (quizá incluso, si podremos atravesarla) dependerá de cómo respondamos éticamente a la idea de que vivimos en un único mundo». SINGER,

8 NAGEL, 2005: 113. 2003: 25 . 
die duda de que estas últimas imponen algún tipo de responsabilidad ética y política sobre los más favorecidos. En lo que no parece haber tanto acuerdo es en el tipo de deberes que conllevaría su erradicación o, cuando menos, el alivio de sus efectos ¿Es correcto afrontar el desafío ético que representan como una cuestión de humanidad, o está en lo cierto SEN al señalar que cuando, a lo largo y ancho del planeta, la gente se agita para exigir más justicia global no está reclamando algún tipo de «humanitarismo mínimo»? ? . En tal caso es ¿debemos incluir en el contenido de la justicia global algún principio corrector de las desigualdades de recursos u oportunidades? ${ }^{10}$.

Una de las principales razones para responder negativamente a esta segunda posibilidad gira en torno al carácter institucional en lugar de moral del concepto de justicia distributiva. La interpretación más fuerte y polémica de esta tesis considera que las instituciones políticas juegan un papel decisivo, no solo de cara a la implementación de las exigencias de ésta, o a la determinación de los criterios distributivos para cada reparto, sino también con vistas a la formulación de los primeros principios. Es lo que se conoce como concepción de justicia dependiente de la práctica. Esta última ofrece una de las razones más poderosas para desacreditar la que, al menos para la primera generación de cosmopolitas modernos, constituyó la vía más habitual para afrontar las enormes diferencias socioeconómicas individuales como un problema de justicia también más allá de las fronteras: el «igualitarismo de la suerte». Este trabajo examina las claves desde las que podría construirse una justicia distributiva global a partir de la corrección o moderación de la concepción de la justicia dependiente de la práctica a un doble nivel. En primer lugar, apuntando a la necesidad de combinar adecuadamente elementos independientes (racionales, morales o ideales) y dependientes de la práctica de cara a evitar vaciar a la teoría de la justicia de su componente crítico. En segundo lugar, ampliando, con el auxilio de la noción de «justicia de trasfondo» y de la concepción sistémica de la coacción, el tipo de prácticas que generan demandas morales de la particularidad y exigencia característica de la justicia distributiva.

\section{EL IGUALITARISMO GLOBAL DE LA SUERTE}

El cosmopolitismo constituye uno de los principales puntos de vista desde los que ha venido afrontándose el reto de tomar el pulso ético y político a las transformaciones sociales y económicas características de la globalización. En el plano de la justicia social, esta perspectiva se caracterizaría por defender la aplicación de un principio corrector de las desigualdades de recursos, bienestar u oportunidades entre los individuos que han nacido o residen en distintas comunidades políticas, similar al que podría imperar en el seno de cada una de éstas ${ }^{11}$. En parte, si BEITZ, POGGE o BARRY han recibido el

9 SEN, 2010: 57-58.

10 Vid. IgLESIAS, 2006.

${ }^{11}$ Existen, como es sabido, distintas concepciones de los bienes que demanda la igualdad: de oportunidades a través de la aplicación global del principio de diferencia (BeITZ, Mollendorf, CANEY), en el alivio del sufrimiento (SINGER), en la satisfacción de las necesidades básicas y urgentes (Iglesias), en la protección de las capacidades básicas (Nussbaum, COHEN), en la libertad real para todos (VAN PARIJS), etc. Siguiendo a L. HIERRO, todas estas concepciones coinciden en lo siguiente: para todas ellas, el ideal moral de la igualdad es la igualdad entre todos los seres humanos en los recursos adecuados para satisfacer las necesidades básicas 
calificativo de cosmopolitas ha sido, precisamente, por la defensa que realizan del alcance global (mundial, universal) de los principios de la justicia distributiva.

No obstante, por «cosmopolitismo» o «cosmopolita» no se entiende, a veces, única o principalmente un atributo referido al alcance de estos principios cuanto una cierta forma de justificar o, cuando menos, de ofrecer razones en su favor que, en este caso, se traduciría en una exigencia de corregir las desigualdades económicas y sociales individuales al margen, o más allá, de las fronteras. Según esto, el cosmopolitismo sería únicamente una justificación más — si bien seguramente la más habitual— de la justicia global igualitaria. La misma descansaría en las dos siguientes premisas: en primer lugar, el individualismo ético, esto es, la defensa de la igualdad moral de todos los individuos en tanto que seres humanos; $\mathrm{y}$, en segundo lugar, la irrelevancia moral de factores como la nacionalidad, la ciudadanía o el lugar de residencia, de cara a justificar atribuir preferencia a unos individuos frente a otros. A una y otra exigencia no se le ha otorgado, no obstante, siempre el mismo peso en la gramática cosmopolita. Seguramente, en las versiones estoica y kantiana, el valor moral de la común humanidad y, a lo sumo, el distanciamiento — que no irrelevancia - respecto de las identidades e intereses vinculados al lugar de nacimiento, ha sido el aspecto fundamental del ideal de la ciudadanía mundial. Por el contrario, si bien cabe encontrar algún precedente en el cosmopolitismo de la ilustración, en la literatura cosmopolita de las últimas décadas el segundo aspecto ha ido cobrando, progresivamente, mayor protagonismo que el primero. Aunque se continúe insistiendo en el individualismo moral frente al holismo más o menos intenso de las diferentes concepciones comunitaristas, el aspecto «negativo» ha ido haciéndose cada vez más presente en la justificación de una justicia sin fronteras. Así, por ejemplo, NussBAum, aunque parta de una definición del ideal cosmopolita como aquel que define a «la persona cuyo compromiso abarca toda la comunidad de los seres humanos» ${ }^{12}$, termina poniendo el acento en que las fronteras del grupo, la nación y el Estado carecen de significado moral o son éticamente irrelevantes por depender del azar ${ }^{13}$.

El protagonismo que en la primera generación de cosmopolitas modernos sobre la justicia habría cobrado el argumento de la irrelevancia moral de las fronteras no puede explicarse si no es por referencia a la enorme influencia ejercida por la obra de RAWLS. Al menos en apariencia, esta justificación del alcance global de la justicia distributiva se hallaría implícita en algunas tesis y reflexiones de quien ha demostrado ser, no obstante, uno de los más señalados críticos del cosmopolitismo. En $A$ Theory of Justice aquél afirmaba que las pretensiones y obligaciones morales no deberían depender de factores moralmente arbitrarios en tanto que inmerecidos, como serían la dotación natural o la posición social inicial, sino de las elecciones y decisiones individuales ${ }^{14}$. Aunque haya ciertos elementos de su teoría (como el rechazo del sistema de libertad natural) que hacen factible otra lectura de su concepción de la igualdad, lo cierto es, tal y como

de forma que permitan a todos y cada uno desarrollar de forma equiparablemente autónoma y libre su propio plan de vida. HIERRO, 2005: 358.

12 «El nacimiento en una nación y no en otra es un puro accidente. Por ello no debemos permitir que las diferencias de nacionalidad, de clase, de pertenencia étnica o incluso de género erijan fronteras entre nosotros y ante nuestros semejantes». NuSSBAUM, 1999: 14.

13 Ibid., 18.

14 RAWLS, 1979: 123-126. Sobre las diferencias entre la concepción de la igualdad de RAWLS y el igualitarismo de la suerte, vid. SCHEFFLER, 2003, 12 y 25 y ss. 
se pone de manifiesto cuando él mismo se desmarca del que denomina «principio de compensación», que RAWLS no llega a sostener que la justicia exija suprimir por completo la incidencia de factores como la buena o la mala suerte en la distribución de los bienes ${ }^{15}$. Como podremos apreciar, la evolución posterior de su pensamiento, en Political Liberalism y en la edición corregida de Justice as fairness, descarta definitivamente esta lectura del igualitarismo rawlsiano. No obstante, inmediatamente después de la publicación de $A$ Theory of Justice, comenzará a cobrar fuerza la interpretación según la cual RAWLS no habría sido consciente de las implicaciones de su propio argumento, y que la justicia debería perseguir, eliminar y compensar las posiciones de desventaja surgidas de factores moralmente arbitrarios, no sólo los de carácter social sino también los derivados de las cualidades naturales ${ }^{16}$. Defensores de la igualdad como ARNESON, DWORKIN o COHEN comenzarán a defender que es injusto que alguien se encuentre peor que otros debido a la mala suerte, y que el objetivo de la justicia igualitaria consistiría en eliminar, en la medida de lo posible, el impacto de aquélla sobre la vida de las personas. Esta justificación de la justicia distributiva igualitaria recibirá el nombre de «igualitarismo de la suerte» (luck egalitarism).

El igualitarismo de la suerte es una perspectiva ética que puede resultar más o menos exigente en función de, principalmente, dos factores. El primero de ellos sería la finalidad que se atribuya a la igualdad en relación con las circunstancias no elegidas. A diferencia de RAWLS, que sostiene que el principio de diferencia sólo persigue mitigar los efectos de la suerte ${ }^{17}$, la postura genuinamente luck-egalitarian interpretaría la función del principio de diferencia en un sentido más ambicioso: en el de que el objetivo primordial de la igualdad sería eliminar y compensar a las personas de la mala suerte inmerecida que supone, entre otras circunstancias, haber nacido con una dotación natural pobre, o sufrir accidentes y enfermedades, a través de una redistribución de la riqueza ${ }^{18}$. En segundo lugar, la ambición del igualitarismo de la suerte irá unida al alcance espacial o geográfico que se atribuya a sus exigencias. De la lectura del cosmopolitismo de BEITZ, BARRY o CANEY parecería desprenderse el carácter intrínsecamente universal de esta concepción de la igualdad. Sin embargo, ¿es el igualitarismo de la fortuna «naturalmente» global, de un modo similar a, como apunta PARFIT, lo sería el prioritarismo? ${ }^{19}$.

En contra de una respuesta afirmativa pesaría el dato que uno de los principales defensores del igualitarismo de la suerte doméstico, como es DwORKIN, no dé el paso de admitir esta posibilidad. Así se desprende tanto de la consideración de la igualdad como la virtud «soberana» de la comunidad política, como de la exclusión de los derechos económicos de la nómina de los derechos humanos básicos ${ }^{20}$. Con ello se pone

15 RAWLS, 1979: 124-125.

16 KYMLICKA, 1995: 86-88.

17 FreEman, 2002: 117. De ahí que, a juicio de SCHEFfler, RaWls no sería el héroe que esperaban los cosmopolitas ya que en ningún momento afirma que los factores moralmente arbitrarios no deban jugar ningún papel en la distribución, sino que ésta no deba estar impropiamente influida por ellos. SCHEFFLER, 2008: 69.

18 ARnESON, 2008: 80.

19 PARFIT, 1999: 21. Para una defensa de la justicia global basada en un principio de prioridad de la satisfacción de las necesidades más básicas y urgentes, vid. IGLESIAS, 2005: 54-66, y TuRÉGANO, 2010: 228-238. En contra del carácter naturalmente cosmopolita del prioritarismo, vid. HoLTUG, 2009.

20 Dworkin, 2003, 16. A juicio de BROwn, Dworkin contempla los derechos igualitarios como algo que poseemos en virtud de nuestra membresía en la comunidad política particular en la que nacemos y únicamente en relación con nuestros compatriotas. BROWN, 2009, 85. En un mismo sentido TuRÉGANO, 2010: 201. 
de manifiesto que no existe una conexión lógica o necesaria entre las premisas éticas del igualitarismo de la suerte y el igualitarismo global, tal y como lo pone también de manifiesto que un destacado portavoz del estatismo como NAGEL reconozca la plausibilidad moral del primero y se muestre abiertamente contrario al cosmopolitismo igualitario ${ }^{21}$. Lo cierto es, sin embargo, que a lo largo y ancho del planeta encontramos realidades y datos tan abrumadores ${ }^{22}$, que explican que una lectura de la justicia como la que suscriben los igualitaristas de la suerte ofrezca un considerable atractivo. Como escribe BERTRAM, el hecho de que la esperanza de vida de un niño que tiene la suerte de nacer en Boston, Massachusetts o Barcelona sea muy superior a la de otro que lo hace en Burundi o Bogotá exige a gritos una rectificación ${ }^{23}$. No es sorprendente, pues, que esta concepción de la igualdad haya sido uno de los pilares sobre los que han construido Beitz, Pogge, Barry y, más recientemente, Caney, Tan, Mollendorf o Brown, sus defensas de la regulación igualitaria de las desigualdades (de oportunidades antes que de recursos) globales. Y si, como ya hemos destacado, los primeros cosmopolitas igualitaristas globales de la suerte (en adelante IGS) partían de una lectura discutida de la obra de RAWLS, quienes les siguen actualmente hacen otro tanto con la teoría de la igualdad de DworKin. A juicio de estos últimos, la distinción entre la suerte dependiente de factores totalmente imprevisibles (brute luck) y la derivada de hechos en mayor o menor medida anticipables y evitables (option luck) ${ }^{24}$, podría ser extendida, de forma coherente, al contexto internacional ${ }^{25}$.

Los hechos que, a juicio de los IGS, determinan un nivel de bienestar u oportunidades no merecido sino fruto de la suerte bruta que debe ser mitigado o compensado, son fundamentalmente dos. El primero es el acceso a los recursos naturales. El hecho de que, por azar, alguien se encuentre en una posición ventajosa al respecto no proporcionaría una razón para excluir a los demás de los beneficios que puedan derivarse de aquéllos. En un mundo de escasez, la apropiación de recursos valiosos por algunos dejaría a otros, comparativa y quizás fatalmente, en desaventajada. Por esta razón, BEITZ y POGGE y, más recientemente BROwN, insisten en que debe exigirse un principio redistributivo de los recursos que proporcione a cada sociedad una oportunidad equitativa de desarrollar unas instituciones políticas y una economía capaces de satisfacer las necesidades básicas de sus miembros ${ }^{26}$. Sin embargo, más que la distribución natural de los recursos, la principal lotería que, ya sea mediante su reflejo institucional o como un hecho bruto, impondría arbitrariamente a unos una posición peor, o mucho peor, que a otros sería, bien la del lugar de nacimiento ${ }^{27}$, factor que conlleva una nacionalidad y ciudadanía no elegidas, bien la del lugar de residencia no

21 NAGEL, 2005: 126.

22 Alrededor de 2.800 millones de personas (el 46 por 100 de la humanidad) viven por debajo del umbral de la pobreza que el Banco Mundial fija en dos dólares diarios. Cerca de 1.200 millones viven con menos de la mitad. Cada año mueren unos 18 millones prematuramente a causa de la pobreza extrema y masiva. POGGE, 1995: 14.

23 BERTRAM, 2006: 330.

24 DwORKIN, 2003: 84. La distinción viene a coincidir, en gran medida, con la distinción entre la suerte dependiente de las elecciones y la que derivada de las circunstancias que suscribe RAWLS.

25 BROWN, 2008: 459.

26 Beitz, 1979: 137-141. Pogge, 2005: cap. 8; BRown, 2009: 169-203. Este último defiende, sobre la base del modelo de igualdad de recursos de DWORKIN, una distributiva global más exigente que basada en el principio de diferencia. TuRÉGANO, 2010, 209.

27 Pogge, 1989: 247; Caney, 2001: 125; TAN, 2004: 158. 
elegido $^{28}$. La membresía política puede y suele ser un supuesto de «suerte bruta» que exige una neutralización a través de una justicia distributiva igualitaria ${ }^{29}$.

El carácter azaroso de la membresía política ha dado pie a la que, muy probablemente, sea la tesis más fuerte del IGS: la de que, con independencia de cuáles sean las causas de la pobreza de una sociedad, no puede afirmarse que quienes nacen y florecen en su seno deban ser considerados responsables de su situación. El origen de la mayor o menor riqueza de una comunidad (ya se encuentre en su capacidad para hacerse menos vulnerable a las catástrofes naturales, en el disfrute de abundantes recursos naturales, en la posesión de un mayor grado de capital cultural y científico que la capacite para una mejor gestión económica, o en la sabiduría de sus antepasados para adoptar decisiones acertadas para el futuro) resultaría irrelevante, ya que «no puede afirmarse que los individuos que nacen abora en esa sociedad sean responsables de alguno de esos factores» ${ }^{30}$. El equivalente a nivel doméstico de estas personas se encontraría, más bien, en el niño que sufre las consecuencias de las decisiones imprudentes o irresponsables de sus padres. En tales casos - asevera BEITZ - nos mostramos reacios a considerar a los niños responsables de su propia situación ${ }^{31}$. Lo cierto es que, en el caso de que pertenezcan a una sociedad jerárquica y no democrática, los ciudadanos de los países pobres no han tenido por qué consentir, necesariamente, las políticas y decisiones sociales de sus gobiernos y, en el supuesto de que tales políticas hubieran sido puestas en marcha con anterioridad, tampoco habrían tenido oportunidad de hacerlo. Por tanto - concluye TAN- sus desventajas se deben más a las circunstancias que a las elecciones, y si la justicia ha de ser sensible a las elecciones individuales, e insensible, por el contrario, a las circunstancias, entonces no podemos aceptar que los principios de la justicia distributiva global rechacen esta distinción ${ }^{32}$.

\section{LOS LÍMITES DEL IGUALITARISMO DE LA SUERTE GLOBAL: LA CONCEPCIÓN INSTITUCIONAL DE LA JUSTICIA}

El igualitarismo de la fortuna es una posición seriamente cuestionada. Entre otras razones, se la ha tratado de desacreditar presentándola como una lectura de la igualdad que traiciona el espíritu e, incluso, la letra de la obra de RAWLS (vid. infra). Otras críticas más sustantivas apuntan a las conclusiones inaceptables a las que conduciría defender la vinculación fuerte entre suerte y responsabilidad característica de este igualitaris-

28 FABRE, 2005: 149. Las razones basadas en el carácter azaroso del lugar de nacimiento o residencia están muy presentes en los discursos críticos con las políticas de inmigración de los países más ricos. Así, por ejemplo, J. DE LUCAS insiste en varios trabajos en que la condición de miembro de la comunidad política no puede ser un privilegio vedado a quienes no tuvieron el premio de la «lotería genética o geográfica». DE LUCAS, 2002: 65. Seguramente el pionero en el uso de este tipo de argumentación en el contexto de la admisión e integración de los inmigrantes fue CARENS. Para él, «no es posible sostener restricciones sobre la base de que quienes hayan nacido en un territorio tienen un mejor derecho a los beneficios de la ciudanía que quienes hayan nacido en otro territorio o sean hijos de extranjeros. El lugar de nacimiento y residencia son contingencias naturales “arbitrarias" desde un punto de vista moral». CARENS, 2009: 67.

29 BROWN, 2008: 462.

30 SCHEMMEL, 2007: 58.

31 BEITZ, 1999: 525.

32 TAN, 2004: 73. Vid. en un sentido parecido CANEY, 2002: 115, y KNIGHT, 2008: 727. 
$\mathrm{mo}^{33} \mathrm{y}$, sobre todo, a que la igualdad no es lo opuesto a la mala suerte involuntaria, sino a la opresión, a las jerarquías heredadas del estatus social, las castas, los privilegios de clase y las estratificaciones sociales rígidas ${ }^{34}$. Más recientemente, también se ha puesto de manifiesto, a través de lo que S. HuRLEY denomina «falacia igualitaria», los defectos lógicos del razonamiento mediante el que se construyen las tesis del igualitarismo de la suerte ${ }^{35}$. Mi interés va a centrarse, no obstante, exclusivamente en los ataques contra el igualitarismo de la suerte que comprometen más seriamente sus pretensiones globalistas ${ }^{36}$.

Una de las principales razones esgrimidas para rechazar que la construcción de una justicia distributiva global pueda descansar únicamente en esa concepción de la igualdad es la que considera que tal labor ha de conciliar, inevitablemente, las razones éticas derivadas del azar del nacimiento o residencia en una determinada comunidad política, con el derecho a la autodeterminación de otras. Una crítica más fuerte aún rechaza el argumento al que hacíamos anteriormente referencia según el cual, con independencia de cuáles sean las causas de la pobreza de una sociedad, no puede afirmarse que quienes nacen y florecen en su seno puedan ser considerados responsables de ella. La membresía no elegida en una comunidad en la que las oportunidades o recursos al alcance de sus miembros son comparativamente muy inferiores a los de otros Estados no permite concluir, sin mayores consideraciones, que hayan de ser siempre considerados víctimas de una suerte bruta y no, al menos en ciertas ocasiones, responsables de una suerte elegida. En algunos supuestos, podría considerárseles colectivamente responsables de su situación y no, de modo paternalista, víctimas de ella ${ }^{37}$. No obstante, quizá la principal razón de que la perspectiva de la suerte resulte poco atractiva en el plano global está relacionada con el predicamento tan apreciable que habría adquirido en la literatura iusglobalista lo que POGGE denomina el «cosmopolitismo explicativo», esto es, con la consideración de la pobreza extrema y las enormes desigualdades mundiales como realidades que tendrían su principal causa en el actual orden económicopolítico internacional y, solo excepcionalmente, en las contingencias naturales. No abordaré en este trabajo el interesante debate suscitado a raíz de las críticas anteriores al IGS. Me centraré en otro tipo de reflexiones que no cuestionan tanto el contenido de este argumento como su fuerza para ofrecer una razón suficiente para una justicia distributiva igualitaria.

Sin duda, aplicado al plano global, el igualitarismo de la fortuna ofrece un argumento moral importante para no desentendernos de la situación de los menos aven-

33 BARRY, 2005, cap. V; RiBOTTA, 2010: 236-243.

34 ANDERSON, 1999: 313.

35 Habría un salto inaceptable en el paso de la tesis 1) Es cuestión de suerte que X esté mejor que Y, a la tesis 2) no debería depender de la suerte que X e Y estén igual. El paso de 1) a 2) sería tan falaz como el paso de 3) es cuestión de suerte que X e Y estén igual a 4) no debería depender de la suerte que X e Y estén desigual. Para esta autora, «el hecho de que las personas no sean responsables de la diferencia no conduce a afirmar que sean responsables de la no diferencia». HuRLEY, 2001: 57.

36 Conviene en este punto advertir que un IGS actual como el que propugna BROwN, aun cuando reivindica su aplicación al plano global consideran, admiten que éste, aun siendo un elemento muy importante que teorías como la de POGGE ignoran por completo, no sería el único ni quizá el principal componente de la una justicia distributiva global. BROWN, 2009: 150.

37 El principal defensor de esta tesis es D. Miller. Vid. Miller, 2007: en especial capítulos 4, 5 y 9. Vid. también RAWLS, 1999: 130. 
tajados del planeta. Empero ¿es una razón lo suficientemente fuerte y completa como para fundamentar deberes de justicia también respecto a éstos? La principal razón empleada para poner en entredicho la suficiencia del igualitarismo de la suerte de cara a defender una justicia socioeconómica global gira en torno al carácter conceptualmente institucional de la justicia. Este argumento ofrece, no obstante, versiones parcialmente diferentes en función, por un lado, del modo en que sean definidas las instituciones políticas ${ }^{38} \mathrm{y}$, por otro, del nivel de la teoría de la justicia en el que nos situemos.

\subsection{Las instituciones como objeto de la justicia}

La versión más débil de la conexión conceptual entre la justicia y las instituciones señala que la primera no se aplica a hechos o situaciones naturales, ya que la naturaleza no es un agente que distribuya bienes, cargas o derechos en función de unos u otros criterios. Como señala RAWLS, la distribución natural «no es justa ni injusta, como tampoco es injusto que las personas nazcan en una determinada posición social. Estos son hechos meramente naturales. Lo que es justo o injusto es el modo en que las instituciones actúan sobre estos hechos» ${ }^{39}$. El ámbito de la justicia sería, por tanto, la valoración moral de los juicios, decisiones, acciones e instituciones humanas que atribuyen a alguien algo en cuanto suyo. Siguiendo el esquema clásico que trazara ARISTÓTELES en el capítulo V de la Ética a Nicómaco entre justicia distributiva y justicia conmutativa, podemos concluir que la justicia sería un segmento de la moralidad conceptual e intrínsecamente relacionado con la distribución de cargas o beneficios entre cierta clase de personas y - más que con la compensación, tal y como señala HART- con lo que HIERRO acuerda en denominar reciprocación (intercambio, venganza, reparación y compensación ${ }^{40}$. Por tanto, cabría hablar de desigualdades no sólo moralmente arbitrarias sino también injustas cuando éstas tienen su causa en esquemas institucionales que distribuyen cargas y beneficios, en relación con los criterios distributivos observados por éstos.

No creo que sea del todo correcto, sin embargo, reducir la desacreditación del IGS a la acusación de que incurre en la variante de falacia naturalista negativa consistente, en su caso, en derivar normas de justicia únicamente del hecho fortuito, y por tanto inmerecido, de nacer en un determinado lugar y no en otro. Venir al mundo en un sitio y no en otro constituye un hecho que, como tal, no es susceptible de valoración, sino de verificación o de prueba. Lo cierto, no obstante, es que el nacimiento nunca tiene lugar en un lugar geográfico sin más, sino en el territorio de un Estado, esto es, en un espacio jurídico-político, no sólo en el sentido de hallarse bajo el derecho, sino en el más fuerte

${ }^{38}$ La expresión «instituciones políticas» puede ser entendida en un sentido restringido o amplio. En el primero, denotaría las instituciones asociadas con los procesos políticos (sistema electoral, parlamentario, etc.). En el segundo, abarcaría a cualquier institución que pueda verse afectada por los procesos políticos. En este sentido, incluiría, además de la estructura del gobierno, las principales instituciones jurídicas, económicas e, incluso, culturales. Comprendería, pues, todo aquello que RAWLS designa como la «estructura básica» de la sociedad. GOOdIN, PetTIT y Pogge, 2007: xvii.

39 RAWLS, 1971: 124-125.

40 HART, 1960: 197; Hierro, 2002: 20. 
de ser también un artefacto jurídico. Desde esta perspectiva, el nacimiento en uno u otro Estado no sería un hecho puramente físico, sino un acontecimiento que tiene lugar en un lugar institucionalmente constituido, y es precisamente la trascendencia que esto último tiene para las perspectivas de vida de los individuos lo que los igualitaristas de la suerte consideran moralmente cuestionable. Si — volviendo a RAWLS- justos o injustos no son los hechos sino el modo en que las instituciones actúan sobre ellos, la división del mundo en Estados separados y el tipo de autonomía y relaciones existente entre ellos serían algunos de los principales elementos de un esquema institucional, formado por el derecho internacional y el orden económico mundial, que hace depender el acceso de los individuos a las oportunidades o a los bienes y recursos de circunstancias no elegidas, como son el lugar de nacimiento o residencia. Por todo ello, en la actualidad, algunos de los principales defensores del luck egalitarism suscriben una versión institucional y no puramente apriorística del mismo ${ }^{41}$.

\subsection{El papel de las instituciones políticas en la determinación de los criterios de la distribución. El elemento político de la métrica de la igualdad}

Habría, no obstante, una conexión aún más profunda entre la justicia social y las instituciones. El concepto de justicia distributiva hace referencia a una situación de reparto que requiere las siguientes condiciones previas $\left.{ }^{42}: a\right)$ la condición de receptor del reparto; b) el distribuendum o conjunto de valores positivos y negativos (bienes, cargas, derechos y deberes) a repartir, y $c$ ) unos criterios de distribución de los valores transferidos para cada supuesto de reparto, o, en el caso de que no dispongamos de tales criterios, $c^{\prime}$ ) un procedimiento o autoridad para establecer los criterios de la distribución. El concepto o la forma de la justicia distributiva requiere que el reparto se lleve a cabo de acuerdo con algún criterio; empero, al no establecer ningún método para determinar cuál debe ser el criterio particular adecuado, el fin o propósito del reparto no puede realizarse en el interior de la justicia, sino que debe ser determinado por una autoridad, a través de un proceso que idealmente adoptaría decisiones basadas en la imparcialidad, pero que en la práctica quizá sea, más bien, un ámbito dominado por «la interacción del poder, la persuasión, la simparía y el interés» ${ }^{43}$. Por esta razón, RUMMERS considera que las exigencias particulares de la justicia distributiva no pueden ser determinadas de forma adecuada de un modo apriorístico por filósofos o políticos, sino en el marco de los actuales procesos democráticos ${ }^{44}$. Parece claro, pues, que un estándar de justicia distributiva igualitaria como el principio de diferencia rawlsiano no está en condiciones de proporcionar, dada su generalidad y relativa indeterminación, este criterio de justicia para cada reparto, menos aún si nos situamos en un contexto global y no sólo nacional, en el que resultaría todavía más difícil lograr juicios políticoeconómicos claros para medir la condición de «menos aventajado» ${ }^{45}$. En conclusión, para decirlo con ARISTÓTELES, «la justicia es cosa de la polis» (dikaiosýne politikón) ${ }^{46}$.

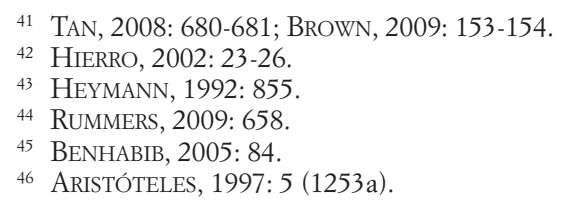


En vista de todo ello, podemos concluir que el concepto de justicia social, en particular, el de aquel aspecto o concepción de la misma dirigido a corregir las desigualdades de oportunidades, ingresos o recursos, remite necesaria o conceptualmente a normas, autoridades o instituciones a las que corresponde determinar, en función del contexto y del peso de las pretensiones en juego, ese criterio para cada reparto. Los cosmopolitas igualitarios de la suerte también reconocen el papel esencial de las instituciones, pero únicamente en su condición de instrumentos imprescindibles para garantizar la aplicación efectiva de las exigencias de la justicia y no, como vemos ahora, de cara a su formulación. Sin embargo, de acuerdo con la lectura del carácter político de la justicia que ahora analizamos, la razón de que las instituciones terminen resultando determinantes no es únicamente que pueden asegurar, dados sus medios económicos y coactivos, el cumplimiento de las exigencias distributivas, sino que, en la determinación de los criterios del reparto, ha de intervenir, necesariamente, una autoridad política ${ }^{47}$. La tesis hobbesiana extra republicam nulla iustitia podría recibir, a la vista de estas últimas consideraciones, una interpretación más compleja ${ }^{48}$. Más que como justificación del iuspostivismo ideológico o del formalismo ético, lo que HoBBES trataría de demostrar sería el carácter conceptualmente político de la justicia ${ }^{49}$.

El examen de la primera, pero sobre todo de la segunda de las versiones de la tesis del carácter institucional de la justicia permite concluir la imposibilidad de deducir responsabilidades de justicia a partir, únicamente, del deber de compensar la mala suerte. En lugar de limitarse a considerarlo exclusivamente un argumento para justificar la necesidad o conveniencia de un tratamiento igualitario de las desigualdades, el luck egalitarism convierte, sin mayores consideraciones, la distinción entre suerte y opción en una razón sustantiva completa acerca del modo en que debe distribuirse cierto bien $^{50}$. El igualitarismo de la fortuna no deja de ser, pues, una intuición o, en el mejor de los casos, una razón en favor de la igualdad o quizá, más bien, de la beneficencia o humanidad ${ }^{51}$; intuición o razón a la que, además, se tacha de ser poco persuasiva e, incluso, desconcertante ${ }^{52}$.

47 En esta línea YPI señala que, a diferencia de la ética, la justicia es por definición comparativa, ya que su sentido es precisamente ofrecer una solución sobre la cuota de reparto de un cierto valor que goce de autoridad y resulte vinculante para los desacuerdos morales entre los individuos. Este tipo de adjudicación entre pretensiones morales rivales precisa de una acción colectiva, a través de un proceso político basado en la imparcialidad. YPI, 2010: 174; En un sentido similar, SCHEMMEL, 2008: 60.

48 HobBes (1651) 1979: 240-242. La expresión utilizada por HOBBES es «commonwealth»: «where there is no Common-wealth, there is no Propriety; all men having Right to all things: Therefore where there is no Common-wealth, there nothing is Unjust». En la versión latina de Leviatán 1678 (Apud Johannem Tomsoni, M., Londini, DCLXXVI, 72). HobBES utiliza la expresión «civitas»: «Nam ubi Suum non est, id est, ubi Proprium non est; ibi Injustum nihil est; ubi Civitas non est, nihil est Proprium».

49 El gobierno, como afirma NAGEL, sería una condición habilitante de la justicia. NAGEL, 2005: 114. L. HiERRo ha resumido acertadamente el significado de esta lectura cuando afirma: «las condiciones de la justicia distributiva parecen confirmar inexorablemente el punto de vista de Hobbes: "sin república no hay Justicia"; esto es, sin un orden establecido es imposible describir las condiciones previas para identificar una situación de reciprocación o una situación de reparto». HIERRO, 2002: 26.

50 TAN, 2008: 674 y 684-685.

51 Sobre el humanitarismo del luck egalitarism, vid. ANDERSON, 1999: 290.

52 SCHEMEEL, 2007: 67. 


\subsection{La formulación de los primeros principios de la justicia social como una labor dependiente de las instituciones. La concepción democrática de la igualdad}

De acuerdo con la argumentación que hemos examinado anteriormente, la justicia tendría un carácter conceptualmente institucional debido a que la determinación de los criterios del reparto no puede llevarse a cabo fuera de un contexto político. Según esto, parece más correcto considerar a las instituciones (autoridades) imprescindibles no únicamente de cara a la realización de la justicia, sino también al objeto de determinar sus contenidos. Bastante distinta es la versión del carácter conceptualmente institucional que examinaremos a continuación. Para ésta no sólo los criterios distributivos para los casos particulares sino todo el contenido de la justicia distributiva, incluidos sus primeros principios ${ }^{53}$, habría de ser formulado, necesariamente, en función del contexto institucional y no, aunque sólo sea parcialmente, también en un plano racional, moral y, sobre todo, ideal.

Para comprender mejor el significado de esta tesis conviene distinguir, tal y como hace GILABERT, tres niveles o dimensiones en las teorías políticas de la justicia: DI. Los principios fundamentales; DII. Los esquemas institucionales destinados a implementar DI; y DIII. Las reformas conducentes a la realización de DII ${ }^{54}$. Como venimos repitiendo, tanto los cosmopolitas como sus críticos están de acuerdo en que la construcción de DII y, sobre todo de DIII precisa conceptual o necesariamente de las instituciones políticas, ya que el diseño de DII forma parte de lo que puede y deber ser decidido en la arena política (gubernamental o parlamentaria), y porque únicamente el Gobierno y la Administración disponen de los conocimientos, los medios y los recursos necesarios para poner en marcha DIII. Sus diferencias, tal y como hemos examinado anteriormente, radican en que los segundos consideran imprescindible la intervención de las autoridades políticas de cara a la formulación de los criterios de cada reparto, momento de difícil encaje en la estructura tridimensional de GILABERT, pero que me inclino por situar en algún lugar fronterizo entre DI y DII, aquel en el que, como hemos señalado, la determinación de los estándares distributivos habría de conciliar principios rivales. Frente a ello, lo que viene poniéndose en duda en los últimos tiempos sería hasta qué punto la formulación de los principios fundamentales (DI) puede llevarse a cabo, única o principalmente, en un plano moral, ideal o apriorístico, en lugar de constituir una tarea mucho más compleja, que habría de combinar el punto de vista ético-filosófico con una perspectiva histórica y sociológica capaz de dar cuenta del modo en que vienen funcionando las instituciones políticas. Lo que vendría a dibujarse aquí es una alternativa entre dos modos de concebir la formulación y justificación de tales primeros principios que, entre otras consecuencias, incidiría decisivamente en el debate entre los cosmopolitas y sus críticos.

Por un lado, se encontrarían quienes sostienen que la formulación de esos principios es una labor que puede desarrollarse independientemente de las instituciones y prácticas ya existentes. Para lo que SanGiovanni, Meckled-García o RonZONI

53 Por ello entendemos aquellos que no derivan de la aplicación de otros principios a circunstancias particulares. SANGIOVANNI, 2008: 137.

54 Gilabert, 2008: 412. 
denominan concepción de la justicia «independiente de la práctica» (practice-independent), las instituciones y prácticas no dan lugar a los primeros principios de justicia, sino que únicamente crean las condiciones de las que depende su aplicación a los supuestos particulares. El principal fin de la justicia es guiar la reforma de las prácticas existentes, siendo una cuestión diferente que ello dependa o no de una profundización en una cierta autocomprensión de la comunidad, o de que sirva para arrojar luz sobre el funcionamiento de sus principales instituciones políticas y sociales ${ }^{55}$. SANGIOVANNI alude precisamente al «igualitarismo de la suerte» como un claro exponente de esta concepción. Tanto éste, como el libertarismo defensor de unos derechos de autonomía preinstitucionales, o quienes apoyan que los dos principios de justicia de RAWLS pueden fundamentarse directamente en la concepción de las personas como sujetos morales (sin necesidad de considerar a la sociedad como un sistema de cooperación basado en el beneficio mutuo), defenderían este modo de formular los primeros principios $^{56}$.

Por otro lado, encontramos a quienes sostienen que el contenido, alcance y justificación de los primeros principios de justicia, en lugar de únicamente su aplicación a los casos concretos, puede variar en función de las instituciones y prácticas que tratemos de regular. Desde esta perspectiva, debería considerarse a los principios de la justicia como interpretaciones de las prácticas existentes que, como tales, deben ajustarse a la descripción de las mismas ${ }^{57}$. Para referirse a este modo de entender la relación entre la justicia y las instituciones y prácticas FREEMAN habla de «constructivismo político», SANGIOVANNI de concepción dependiente de la justicia, mientras que JAMES sostiene que las prácticas sociales actuales representan una «condición de existencia» de la justicia $^{58}$. En lugar de considerar a ésta como un ideal descubierto mediante la deliberación racional, que precisa de las instituciones exclusivamente para su realización, todos estos autores coinciden en que la formulación de los primeros principios exige adoptar una actitud interpretativa compleja, inspirada en el modelo que propone DWORKIN en el capítulo II de su Law's Empire ${ }^{59}$. Este cambio de perspectiva exige investigar hasta qué punto no han sido las instituciones ya existentes, su funcionamiento y el tipo de vínculos que generan entre sus integrantes, las que habrían generado una necesidad o

55 SANGIOVANNI, 2008: 139-144.

56 El cosmopolitismo que viene defendiendo desde hace décadas BEITZ es, seguramente, la teoría que mejor encaja en esta concepción independiente de la formulación de los primeros principios de la justicia distributiva. Así se desprende de su respuesta a la pregunta del papel que habría que asignar a hechos como la interdependencia económica y el correspondiente desarrollo de una estructura normativa global. A su juicio, tales hechos resultan relevantes en el plano de la realización o eficacia de la justicia, pero no en el de la justificación de sus principios. BEITZ, 1979: 204.

57 VALENTINI, 2010: 8.

58 FreEMAN, 2006: 41; SANGIOVANNI, 2008: 138, 2008; JAMES, 2005: 295.

59 DwORKIN distingue tres fases en toda interpretación constructiva. En la primera o «preinterpretativa», los actores identifican el objeto provisional y el contexto de la interpretación, discriminado la práctica en cuestión de otras prácticas diferentes. Esta primera fase exige un importante grado de consenso en el seno de la comunidad interpretativa. En la segunda etapa, la fase «interpretativa», los participantes tratan de dar sentido a los datos identificados en el estadio anterior, reconstruyéndolos a la luz de algún propósito o razón justificatoria general. Para evitar una interpretación arbitraria, dicha interpretación ha de superar el test o dimensión de adecuación (dimension of fit). La dimensión de adecuación restringe las posibilidades de atribuir una justificación general o un propósito abstracto a la práctica. Finalmente, en el transcurso de la fase los participantes construyen diferentes concepciones desarrollando la justificación general de la práctica para mostrarla desde su mejor perspectiva. DwORKIN, 1986: 65-66. 
demanda de igualdad comparativa sui generis. Como sostiene uno de los principales abogados de esta concepción:

Nos movemos desde la razón de ser y el fin de las instituciones y de las razones de quienes están implicados en ellas para apoyarlas al modo en que aquellas configuran las relaciones entre los participantes. Nos preguntamos: ¿De qué modo alternan las instituciones las relaciones que mantienen las personas entre sí? ¿Qué tipo de interacciones llegan a hacerse posibles en el marco de esas instituciones? ¿En qué medida generan las instituciones interdependencia entre sus participantes y de qué naturaleza es tal interdependencia? Y, quizás lo más importante ¿cuál es el papel que pretende jugar la justicia entre los participantes? ¿De qué forma emerge la exigencia de la justicia en el seno de los contextos históricos y políticos contingentes constituidos por las instituciones? ${ }^{60}$.

Si para el IGS el carácter inmerecido de las posiciones de desventaja originadas en factores azarosos constituye una razón completa para la corrección de las desigualdades sociales, para los defensores de la concepción dependiente el fundamento de tal principio debe buscarse en una razón interna a las mismas instituciones. Puesto que lo verdaderamente importante no son tanto los bienes que se distribuyen como las relaciones sociales en las que tiene lugar la distribución ${ }^{61}$, la igualdad económica no sería, en primer término, un ideal distributivo dirigido a compensar la mala suerte, sino un ideal moral regulador de las relaciones entre conciudadanos. Para que cobren vida sus exigencias, no es suficiente con el reconocimiento del idéntico moral de todas las personas, sino que es necesario, además, que las relaciones entre ellas en determinados contextos posea una cierta estructura o carácter ${ }^{62}$. Los principios de justicia no funcionarían, pues, como un fin ideal, sino como una constricción moral, como una exigencia sobre el modo en que la práctica debe ser desarrollada ${ }^{63}$.

Pero ¿qué hechos y valores presentes en las relaciones entre los ciudadanos serían relevantes para justificar que la justicia socioeconómica igualitaria opere únicamente en ese contexto? En este punto, las concepciones estatistas y dependientes de la justicia apelan a dos tipos de razones que, si bien no son totalmente distintas o inconexas, ponen el acento en dimensiones diferentes de la estructura y el funcionamiento de las comunidades políticas estatales. Para lo que ANDERSON denomina «concepción democrática de la igualdad», la justificación para que la interacción entre los ciudadanos deba estar presidida por una demanda de igualdad comparativa sui generis es que éstos deben apoyar e imponerse mutuamente solo aquellas instituciones políticas, económicas y sociales que puedan razonablemente aceptar. Un marco institucional que permitiese demasiadas desigualdades económicas y sociales sería un ejemplo de

60 SANGIOVANNI, 2008: 150; en un mismo sentido SCHEFFLER, 2008: 75.

61 A la vista de ello, Julius concluye que la justicia económica sería asociativa y no distributiva (allocative). Su función no es evaluar las respuestas a los problemas distributivos que puedan materializarse cada vez que surge la posibilidad de aumentar o disminuir los bienes que poseen las personas con independencia de quienes sean, sino las historias de interacción entre las personas. Una cierta clase de interacción hace surgir demandas morales inusuales que, en parte, son satisfechas asegurando que la interacción suele generar distribuciones especiales de bienes. JULIUS, 2006: 176-177. En un mismo sentido DANIELS, 2003: 246; TAN, 2008: 666; FREEMAN, 2002: 7, 50.

62 ANDERSON, 1999: 313-314; SCHEFFLER, 2003: 21 y 33. La diferencia, pues, entre los defensores de una concepción justice-dependent, basada en la igualdad democrática, y la practice-independent es que, para estos últimos, la igualdad moral de las personas nos dice directamente lo que nos debemos unos a otros, mientras que, para los primeros, ello depende del tipo especial de instituciones en el que participemos. VALENTINI, $2010: 11$.

63 JAMES, 2005: 295. 
marco razonablemente inaceptable. De ahí que la igualdad democrática exija, entre otras cosas, la regulación de esas desigualdades entre los ciudadanos a través de un principio distributivo que asegure, tal y como asevera el propio RAWLS, que la brecha entre ricos y pobres no exceda de lo permitido por el ideal de la reciprocidad democrática ${ }^{64}$. Como dirá también en la edición corregida de Justice as fairness, la intención del principio de diferencia:

no es simplemente asistir a los que salen perdiendo por accidente o mala fortuna (aunque esto deba hacerse), sino, más bien, colocar a todos los ciudadanos en una posición en la que puedan gestionar sus propios asuntos partiendo de un nivel adecuado de igualdad social y económica. Los menos aventajados no son, si todo va bien, los desafortunados y desventurados —objetos de nuestra caridad y compasión, aunque mucho menos de nuestra piedad - sino aquellos a los que se debe reciprocidad en nombre de la justicia política, justicia política para una totalidad de ciudadanos libres e iguales. Aunque controlen menos recursos, cumplen su parte plenamente de un modo que es reconocido por todos como mutuamente ventajoso y consistente con el autorrespeto de cada cual ${ }^{65}$.

Lo que provoca la presunción especial en contra de las desigualdades no es el principio según el cual nadie debería encontrase peor que otros debido a algo de lo que no es responsable ${ }^{66}$, sino el sentido de la reciprocidad propio de la representación como ciudadanos. La justicia distributiva constituiría, de esta forma, una respuesta a los problemas que puede conllevar la cooperación social y política entre conciudadanos, siendo su función en dicho contexto proporcionar estímulos para la aceptación del sistema por los menos aventajados de éste ${ }^{67}$. Por tanto, el error del igualitarismo de la suerte habría sido sostener una concepción puramente individualista de la igualdad en lugar de centrarse, como hubiera sido lo correcto, en la dimensión social que este valor posee en las sociedades democráticas ${ }^{68}$.

Si la concepción democrática de la igualdad acentúa la dimensión horizontal o social de este valor, la perspectiva que nos ofrecen NAGEL y BLAKE hace otro tanto con su dimensión vertical o estrictamente política. En su caso, la justicia distributiva funciona como un valor dirigido a justificar la coacción estatal, situándose así en las coordenadas de ese liberalismo que, además de defender la supremacía del valor de la autonomía individual, también sostiene que la mayor amenaza para ésta proviene de la coacción que detentan los poderes públicos. Desde esta óptica, la sujeción al orden coactivo estatal sólo será legítima si respeta la autonomía personal, lo cual se traduce, entre otras cosas, en que debe resultar aceptable para quienes están sujetos al mismo. La función y el sentido del principio de diferencia o cualquiera otro ideal de igualdad distributiva es, precisamente, ofrecer a los ciudadanos razones para aceptar seguir formando parte del esquema de cooperación social impuesto coactivamente (BLAKE), o en virtud de un orden jurídico que les impone coactivamente ser, al mismo, autores y sujetos (NAGEL).

64 RAWLS, 1998: 114.

65 RAWLS, 2002: 190.

66 NAGEL, 2005: 118.

67 SAnGiovanni, 2007: 28. Como señalan también R. Miller, la obediencia y aceptación del sistema jurídico a través del que se imponen los términos de la cooperación no puede provenir exclusivamente de la satisfacción de las necesidades más básicas, sino de la mejora de la situación comparativa en relación al resto de los miembros del grupo a través, por ejemplo, de la aplicación de un principio de diferencia como el que propone RAWLS. MILLER, 1998: 213.

68 TAN, 2008: 668. 


\section{DEL ESTATISMO AL GLOBALISMO DEPENDIENTE DE LA PRÁCTICA}

Al margen de presentarse como la crítica más fuerte de lo que YPI llama el cosmopolitismo naif o ingenuo ${ }^{69}$, ¿resulta aceptable la concepción de la justicia dependiente de la práctica? Por otro lado, de asumir que se trata de una metodología adecuada para formular los primeros principios de la justicia cestaríamos eliminando con ello la posibilidad de una justicia socioeconómica global, o puede esta última ser construida también a partir de la interpretación de ciertas prácticas?

La respuesta al primero de estos interrogantes exige no perder de vista que, en el plano de la justicia global, cobra una especial intensidad una cuestión que viene dominando las reflexiones de algunas de las más importantes voces de la filosofía política contemporánea. Me refiero al reto que supone lograr que la teoría política (en particular, la de la justicia), además de moralmente deseable, sea también realizable en la práctica. Para lograrlo, cualquier concepción de la justicia debería evitar dos extremos. Por un lado, un excesivo apego a los hechos que la inhabilite para criticar las injusticias sociales, hasta el punto de poder terminar convirtiéndola en una defensa cínica del statu quo. Por otro, no pasar de ser una utopía idealista, sin posibilidad alguna de ser llevada a la práctica. No es exagerado afirmar que la búsqueda de ese punto arquimédico que evite los extremos señalados, aunque presente ya en el cosmopolitismo kantiano ${ }^{70}$, se ha convertido en una de las principales obsesiones para algunas de las más importantes voces de la filosofía política de las últimas décadas y, en particular, para quienes se vienen ocupando de la justicia global. Éste fue el espíritu que presidió la redacción de esa «utopía realista» que pretende ser, a juicio de su autor, The Law of Peoples, y anima las reflexiones sobre este tema de D. MiLLER ${ }^{71}$.

La búsqueda de este equilibrio ha provocado que los hechos y, en especial, las instituciones políticas y sociales, hayan ido adquiriendo un papel cada vez más importante en las teorías de la justicia. Resulta cada vez menos aceptable que éstas puedan seguir construyéndose de un modo totalmente apriorístico o ideal, sin tomar en consideración los esquemas institucionales e, incluso, las medidas y reformas más concretas (fiscales, administrativas, presupuestarias, etc.) dirigidas a realizar sus contenidos ${ }^{72}$. No obstante, el debate no gira tanto en torno a si los hechos deberían estar o no más presentes en la teoría política de la justicia, como a en qué medida y, sobre todo, en qué

69 YPI, 2010.

70 CAVAllar, 1999: 3-4.

71 Miller, 2007: 18-20, y 2008, 553.

72 En la actualidad muchos autores están preocupados por las formas de concretar en las instituciones las teorías normativas. Este destaca las aportaciones The Cost of Rights, de S. WHITE, ¿Por qué la libertad depende de los impuestos?, de S. Holmes y C. SunsteIn, y El mito de la propiedad: impuestos y justicia de L. MuRPHY y T. NAGEL. Especialmente las dos últimas introducen el tema del papel del sistema fiscal en la teoría de la justicia. Pérez ReY, 2011. Otro de los temas del pensamiento político de las últimas décadas en el que también se ha puesto de manifiesto esta tensión entre los componentes ideal e institucional de la teoría es en la democracia deliberativa. Mientras que en la primera generación de teóricos deliberativos (HABERMAS, RAWLS, Elster) la teoría se situaba un plano casi totalmente ideal, en las siguientes generaciones, particularmente en la última, los aspectos institucionales habrían adquirido progresivamente una mucha mayor relevancia. No obstante, algunos de sus más destacados defensores insisten, en respuesta a quienes tildan al modelo deliberativo de un excesivo idealismo, en el carácter justificativo, reconstructivo y por tanto ideal, en lugar de empírico, de esta teoría. Vid. MARTí, 2006: 22-23. 
fase o momento de la misma deben ser tomados en consideración. Hasta hace poco, el punto de vista más extendido ha sido el que estimaba que los hechos políticos y sociales (las instituciones, la coacción, la cooperación social basada en la reciprocidad, etc.) jugarían un papel progresivamente más importante conforme más cercana se encontrara la teoría al momento de su aplicación o implementación en circunstancias no ideales, esto es, en DII y sobre todo DIII, pero no así en la formulación de los primeros principios de la justicia o DI. Este momento pertenecería a la parte ideal de la teoría, en la que los únicos elementos a tomar en consideración serían ciertas características inamovibles de la condición humana y del mundo en el que vivimos: las conocidas «circunstancias de la justicia». Los estatistas sofisticados sostienen, por el contrario, que los hechos no ideales deberían jugar un papel muy importante también en este primer estadio de la teoría de la justicia.

¿Resulta aceptable el balance entre lo moralmente deseable y lo realizable que ofrece la perspectiva interpretativa de la justicia? Si lo que ésta termina defendiendo es que las prácticas y creencias sociales surgidas en un cierto marco político no sólo condicionarían sino que determinarían por completo el contenido de los principios fundamentales de la justicia, la respuesta es abiertamente negativa. Una cosa es que la justicia no pueda consistir únicamente en razones morales a priori, que el análisis de las condiciones de su realización deba ser un elemento importante de la investigación de su principios ${ }^{73}$, y otra muy distinta que toda su contenido sea completamente interpretativo y sociológico y no, en cierta medida, también ideal. Conviene recordar que precisamente DwORKIN, el padre del concepto de interpretación constructiva, en el capítulo décimo de $A$ matter of principles, que lleva por título «Lo que no es la justicia» (What Jutice isn't), rechaza expresamente la aplicación de esta metodología a la hora de diseñar conceptos morales elevados, como es el caso de la justicia. Ésta —asevera DWORKIN- «no es nuestro espejo sino nuestra crítica» ${ }^{74}$. Por tanto, salvo que se suscriba un contextualismo ético muy fuerte, exclusivo de los enfoques comunitaristas antiliberales, no es fácil encontrar una concepción de la justicia doméstica totalmente dependiente ${ }^{75}$. Aunque sea en un grado menos intenso, respecto a la justicia distributiva y los derechos socioeconómicos sería extensible la conclusión de HABERMAS de que «la difusión global de los derechos humanos requiere una justificación independiente» ${ }^{76}$.

¿Supera el estatismo dependiente de la práctica este último test? Debe admitirse, más allá de sus posibles defectos lógicos ${ }^{77}$, que esta concepción de la justicia conecta con ciertas intuiciones y creencias bastante extendidas. No es nada contraintuitivo

73 TuRÉGANO, 2010: 240.

74 DwORKIN, 1989: 219.

75 Como apunta el propio SANGIOVANNI, la versión institucional que él defiende asumiría el principio $a$ priori de la igualdad moral de todas las personas SANGIOVANNI, 2008: 147.

76 HABERMAS, 2010: 22.

$77 \mathrm{Al}$ menos formalmente, el liberalismo social parece ser redundante e, incluso circular: justifica el carácter estatal de la justicia distributiva a partir de las relaciones sui generis entre ciudadanos y, al mismo tiempo, parece sostener, como hace FREEMAN, que la justicia distributiva debe ser estatal y no global para preservar la especificidad de la cooperación entre conciudadanos. A su juicio, «sostener que el principio de diferencia debe ser aplicado globalmente, al margen del tipo de cooperación que existe entre las personas, implica que no hay nada especial en la cooperación política y social que tiene lugar en el marco de las instituciones sociales básicas: más aún, implica que la cooperación democrática y social no tiene ninguna incidencia en las cuestiones de justicia distributiva». FREEMAN, 2006: 59. 
considerar que el marco institucional en el que se desarrollan las relaciones entre conciudadanos termina por constituir una asociación sui generis, en la que la interactuación e interdependencias adquieren especial densidad, y que ello podría terminar proyectándose sobre los principios de justicia que las regulan. Mientras los comunitaristas más conservadores sitúan ese vínculo especial en factores de tipo cultural o identitario, los partidarios de una concepción constructiva de la justicia, como RAWLS o MILLER, apelan a elementos más débiles, como la noción de «simpatías comunes», en el caso del primero, o la solidaridad basada en la identidad compartida, en el del segundo. NAGEL y BLAKE o SANGIOVANNI hacen referencia a ciertos hechos institucionales mucho más asépticos. Se considera, además, que esta caracterización del ámbito de los conciudadanos como un ámbito específico de la justicia ofrece una perspectiva adecuada para apoyar un cierto grado de la preferencia — que no exclusividad- de las responsabilidades respecto a los compatriotas frente a las que se tienen frente a los extranjeros. ¿Tendría todo ello cabida en una teoría de la justicia que incorpore entre sus primeros principios exigencias como la igualdad moral o la dignidad? Seguramente ésta es la gran pregunta sobre la que gira, en último término, la polémica entre liberales estatistas y cosmopolitas. En favor de una respuesta positiva cabría alegar que el estatismo moderado no niega que existan responsabilidades hacia los más desaventajados; lo que rechaza es que estas deban basarse en un principio corrector de las desigualdades similar al que propone RAWLS para las comunidades autocontenidas. En su lugar - lo que quizá no sea poco ${ }^{78}$ - impone a los pueblos aventajados unos deberes de acabar con la privación absoluta, calificados como de beneficencia o humanidad. Parte del liberalismo, asumiendo el calificativo de «cosmopolitas débiles», está convencido, pues, de que el reconocimiento de ciertos grados de prioridad hacia los conciudadanos podría ser conforme con los primeros principios de la justicia, incluida la igualdad ${ }^{79}$.

A la vista de estas últimas consideraciones, podemos concluir que el principal inconveniente de las concepciones dependientes de la práctica no radica en su concepción de los principios de la justicia distributiva como exigencias que cobran vida en el contexto de prácticas cooperativas de especial intensidad, sino en el modo en que rechazan o no muestran adecuadamente que, en la justificación de los primeros, han de estar presentes las exigencias ideales independientes. Introducida esta corrección, creemos que el constructivismo parcialmente dependiente ofrece un modo de concebir la justicia socioeconómica que ofrece considerables atractivos. Precisamente, algunos de los recientes desarrollos de la teoría de la justicia socioeconómica global serían un buen exponente de un constructivismo político o de la justicia que combina, de forma equilibrada, elementos dependientes e independientes. Aunque, obviamente, no compartan las tesis del estatismo sobre el alcance de la justicia distributiva, en lugar de continuar apelando únicamente a los argumentos tradicionales del IGS (la exigencia de compensar un acceso inmerecido a unos recursos naturales insuficientes o una ciudadanía en un Estado desaventajado), parte de la teoría de la justicia socioeconómica global habría terminado asumiendo el carácter parcialmente dependiente de la práctica de este valor también más allá de las fronteras. De acuerdo con esta perspectiva, el rechazo de la concepción estatista no residiría en su visión de la justicia socioeco-

\footnotetext{
78 YPI, 2010: 180.

79 Vid. ARCOS, 2009: 201-205.
} 
nómica como un valor vinculado o dependiente, sino en la definición tan estrecha que realiza del tipo de prácticas que generan demandas morales de esta particularidad e intensidad.

Los datos preinterpretativos de los que parten los teóricos de esta última generación de concepciones de la justicia distributiva global serían, fundamentalmente, hechos como la existencia de normas y pautas de interacción, estructuras de gobernanza, y prácticas a diferentes niveles (trasnacional, regional o global) con capacidad para influir decisivamente en las vidas de las personas y que, además, son creadas y aplicadas sin el consentimiento de estas. Tanto BeITZ, como van Parijs, Young, CoHEN y SABEL, BROWN o FRAZER, insisten en que, para activar las exigencias de la justicia distributiva, quizá no sea suficiente con la interactuación e interdependencia entre individuos y sociedades más allá de las fronteras, pero tampoco es necesario que exista un Estado o estructura básica mundial. Es suficiente con que las perspectivas de vida de las personas se vean afectadas por las constricciones que derivan de normas cuya fuerza vinculante es muy fuerte ${ }^{80}$. La mayor incidencia de las prácticas existentes no implica, sin embargo, que los valores ideales e independientes dejen de desempeñar un papel decisivo en la justificación de los principios de la justicia distributiva global. Como fundamento o razón última de la regulación equitativa del comercio internacional, el acceso a los recursos naturales o la redistribución de la riqueza, se mencionan valores abstractos como el principio de que todos los individuos son auténticas fuentes de pretensiones válidas, que todas las personas son fundamentalmente iguales, o el idéntico derecho de todas las personas a vivir existencias merecedoras de serlo ${ }^{81}$. Tampoco significa que estos cosmopolitas suscriban una lectura de la justicia global idéntica a la de los estatistas. Siguiendo la distinción de BARRY ${ }^{82}$, las simpatías de estos enfoques irían dirigidas, en lugar de hacia una concepción de la justicia como reciprocidad (que incluiría la justicia como fair play), hacia una concepción de la justicia como igualdad de derechos, que A. BROwn, por ejemplo, interpreta en el sentido dworkiniano del derecho a una misma consideración y respeto ${ }^{83}$.

\section{ALGUNAS CLAVES PARA EL DESARROLLO DE UNA JUSTICIA DISTRIBUTIVA GLOBAL PARCIALMENTE DEPENDIENTE DE LA PRÁCTICA}

A mi juicio, un constructivismo que combine elementos dependientes e independientes de la práctica representa la alternativa más atractiva de cara a elaborar una teoría la justicia distributiva global. El elemento dependiente aseguraría que la teoría de la justicia, a diferencia del IGS, se sitúe en un plano social e institucional y no sólo ideal, preocupándose, de esta forma, de identificar aquellas reglas, instituciones y prácticas que poseen efectos socioeconómicos que, a la luz de una lectura profunda e ideal de los valores que las inspiran, habrían de ser consideradas objeto de la justicia. El elemento independiente, por su parte, permitiría evitar uno de los mayores inconvenientes de

\footnotetext{
80 Beitz, 1999: 524-525; van Parijs, 2007: 649-650; Frazer, 2008: 126-127; Brown, 2008, 126.

81 BeITZ, 1983: 585; VAN PARIJS, 2007: 650; VAlENTINI, 2010: 19.

82 BARRY, 1982: 226.

83 BROWN, 2009: 128-129.
} 
considerar los principios de la justicia distributiva exigencias que brotan, únicamente, como límites a ciertas prácticas: el apego conservador al statu quo. Como reconoce, incluso, uno de los defensores de esta metodología, el constructivismo rawlsiano no proporciona razones para criticar la existencia o inexistencia de la clase de práctica que condiciona la aplicación de los principios de justicia y no dice nada, ni a favor, ni en contra, del deber (de justicia) de crear nuevas prácticas de cara a lograr que las ya existentes resulten más equitativas.

Este último sería, precisamente, uno de los principales problemas que tratan de afrontar algunas teorías de la justicia global ${ }^{84}$. Lo cierto es que, en muchas ocasiones, los actores globales pueden estar experimentando injusticias, no porque estén sujetos a un orden institucional (global o regional) que les imponga coactivamente reglas injustas, sino, muy al contrario, debido al vacuum institucional o al carácter asimétrico y heterogéneo de la regulación institucional a la que están sujetos ${ }^{85}$. Tanto la ausencia de normas e instituciones, como la deficiente regulación de diferentes contextos transfronterizos de intercambio entre Estados, sociedades e individuos, serían la causa de gran parte de las desigualdades socioeconómicas a las que venimos refiriéndonos. La teoría de la justicia debería ser capaz de dar cabida a estos hechos sirviéndose tanto de nuevas categorías, como de una interpretación más flexible de los conceptos que han venido restringiendo al dominio estatal las fronteras de la igualdad distributiva.

Como ejemplo de la primera causa de injusticia global (ausencia de regulación) RONZONI alude al fenómeno de la tax competition, o competencia fiscal entre los Estados por ofrecer a aquellos individuos y personas jurídicas que pueden permitirse el «shooping trip» entre diferentes ordenamientos jurídicos nacionales ${ }^{86}$, los mayores incentivos fiscales para atraer hasta el interior de sus fronteras inversiones, capitales, empresas y trabajadores altamente cualificados. Una de las peores externalidades generadas por este fenómeno es que sitúa a algunos Estados ante el dilema de, u optar por estimular esa movilidad mediante una rebaja de los impuestos al precio de desmontar sensiblemente el Estado del bienestar, o resistirse a la presión global, manteniendo un sistema impositivo que les privaría, sin embargo, de esa riqueza «cosmopolita» dispuesta a deslocalizarse al mejor postor.

\subsection{La justicia de trasfondo}

Para RonZONI, la inexistencia de una regulación internacional de la competencia fiscal entre los Estados constituye lo que RAWLS llamaría una «injusticia de trasfondo». Este último concepto señala una importante evolución de la función de la justicia en el pensamiento de RAWLS muy interesante, además, de cara a justificar la extensión global de los principios de la justicia distributiva.

84 JAMES, 2003: 313-314. Por esta razón SCHEFFLER concluye: «No es tarea del filósofo imponer límites $a$ priori a las formas políticas y sociales que puedan surgir en nuestro mundo o cerrar la posibilidad de que al menos algunas de esas formas requieran nuevas regulaciones. Esta es una lección que, al menos algunos teóricos anticosmopolitas quizás han negado a veces». SCHEFFLER, 2008: 77.

85 RONZONI, 2009: 243.

86 Ibid., 238. 
Si en sus primeros trabajos, la principal razón por la que la teoría de la justicia debía centrarse en la estructura básica había sido la conocida afirmación de que los efectos de ésta sobre las perspectivas de vida de las personas son «muy profundos» ${ }^{87}$, o que conforman los deseos y aspiraciones de los individuos, en «La estructura básica como objeto»y, posteriormente, en El liberalismo político y en La justicia como equidad, RAWLS va a señalar que papel de las instituciones es asegurar que las acciones de los individuos y grupos se desarrollen en el seno de un marco que garantice «que los acuerdos entre ellos sean libres y que las circunstancias sociales bajo los que son alcanzados sean justas (fair)». RAWLS señala que es muy probable que, aunque tales circunstancias pudieran haber sido justas en un primer momento, los resultados acumulados de muchos acuerdos justos individuales, unido a las contingencias históricas y a la evolución de la sociedad, terminarán con el tiempo por alterar las relaciones y oportunidades de los ciudadanos, dejando de darse así las condiciones de libertad y justicia iniciales. Por tanto, cuando el orden económico de una sociedad surge de la libre negociación entre sus miembros, los ricos pueden emplear su mayor poder de negociación para moldear este orden a su favor, lo que les capacita para expandir su ventaja al capturar una parte desproporcionada del producto social ${ }^{88}$. Para evitar que la interacción económica pueda ser moldeada a través únicamente de la libre negociación, las instituciones han de corregir esta posible desviación del punto de partida inicial asegurando un trasfondo justo a las condiciones en que se dan las acciones de los individuos y grupos. RAWLS advierte que, a menos que la estructura básica sea convenientemente regulada y ajustada, un proceso social inicialmente justo puede dejar de serlo, por muy libres y equitativas que puedan parecer en sí mismas las transacciones particulares ${ }^{89}$. Cabría hablar, en ese sentido, de una tendencia a la erosión de las condiciones de trasfondo que «está activa aun en el caso de que los individuos actúen equitativamente: el resultado global de las transacciones independientes y separadas se desvía de un trasfondo justo, no confluye hacia él [...] en tal caso, la mano invisible guía las cosas en la dirección equivocada y facilita una configuración oligopolítica que culmina en el mantenimiento de las desigualdades injustificadas y de restricciones a las oportunidades equitativas» ${ }^{90}$.

Aunque RAWLS reconoce que permitir que la libre negociación configure los términos de la cooperación económica constituye una amenaza también en el plano internacional ${ }^{91}$, no extienden a este último su idea de la justicia de trasfondo. En contra de este parecer, en la línea sugerida por POGGE y que desarrolla abiertamente RONZONI, creemos que una teoría de la justicia global podría ocuparse de aquellas situaciones en las que la ausencia o el infradesarrollo de unas instituciones mundiales da lugar a injusticias de trasfondo, y apuntar las reformas o desarrollos institucionales necesarios para corregirlas ${ }^{92}$; a fortiori si existen motivos fundados para suponer que éstas habitúan a ser el resultado de las profundas asimetrías de poder entre los Estados y actores inter-

87 RAWLS, 1978: 21-22.

88 POGGE, 2004: 37-38.

89 RAWLS, 1993: 265-266 (301-302 edición española).

90 Ibid., 267 (303).

91 RAWLS: 2001, 42-43 (55).

92 Para una utilización en clave estatista en lugar de globalista de la noción de «justicia de trasfondo», vid. MECKLED-GARCÍA, 2008: 252-259. 
nacionales más ricos y los más pobres ${ }^{93}$. En otras palabras, la cuestión más apremiante no es si tenemos una estructura básica a nivel global, sino (entre una de las principales razones, para asegurar la justicia de trasfondo) si la necesitamos ${ }^{94}$.

El concepto de «justicia de trasfondo» puede ser de gran utilidad de cara a situar en las coordenadas de la justicia distributiva global algunas situaciones en las que la ausencia de una regulación internacional lesiona los esquemas de justicia social doméstica. Además de las ya señaladas, quizá podría añadirse la enorme discrecionalidad que sigue presidiendo el reconocimiento de gobiernos en la práctica internacional de los Estados. Entre los efectos que se derivan de esta costumbre se encontrarían los conocidos privilegios para recibir préstamos en nombre del país (international borrowing privilege) y para disponer de sus recursos naturales (international resource privilege), señalados por POGGE como dos de los mayores exponentes del modo en que el orden económico global actúa como el principal causante de la pobreza mundial. Sin embargo, no termino de ver claro que una teoría de la justicia socioeconómica global pueda descansar únicamente en asegurar una regulación de los intercambios internacionales, o una armonización internacional de los tributos estatales, que garanticen la justicia de trasfondo. Pensemos, entre otros, en los supuestos de «injusticia estructural» a los que alude YounG, cuyo ejemplo paradigmático lo constituyen las sweetshops ${ }^{95}$; o en el régimen actual de las comisiones bancarias a las remesas de dinero transferidas por los inmigrantes a sus países de origen ${ }^{96}$. En estos últimos casos, el orden internacional estaría siendo el causante de la pobreza global, simplemente, por no poner límites al comportamiento tanto de los gobiernos como las grandes empresas y multinacionales. Por tanto, la vía de la justicia de trasfondo resulta aceptable solo si aspira a ser una forma, quizá la más importante pero no la única, de construir la justicia global.

Por otro lado, cuesta imaginar que ésta posea únicamente un componente regulativo y no también redistributivo, ni, en consecuencia, que valores como la solidaridad o la dignidad humana no deban jugar algún papel en el diseño y la puesta en marcha de las reformas institucionales necesarias para lograr la reducción de desigualdades tan ostensibles ${ }^{97}$. El sometimiento de la globalización socioeconómica a estándares de justicia constituye un proceso que puede ser más o menos ambicioso según cuál sea, por un lado, la densidad de la juridificación, del sometimiento al «imperio de la ley» de la misma que se persiga ${ }^{98} \mathrm{y}$, por otro, de si se toma en consideración la corrección, entre otras por la vía de la redistribución, de las desigualdades tan enormes que se aprecian entre los sujetos que actúan de los mercados globalizados. El «dividendo global sobre

93 PEVNICK, 2008: 401-402.

94 ABIZADEH, 2007: 332. Cabría hablar, por ello, de un deber de establecer instituciones apropiadas, $a$ fortiori si observamos que el tipo de globalización jurídica que ido surgiendo al ritmo de la socioeconómica es, como ha señalado LAPORTA, un mundo más de «networks» que de normas, más de información, contacto y negociación, que de gobierno y prescripción de conductas. LAPORTA, 2005: 250.

95 Young, 2007: 107-112.

96 Expertos del Banco Mundial han establecido por su parte que una bajada de únicamente el 5 por 100 del coste de estas transacciones permitiría aumentar en 3,5 billones de dólares por año las sumas enviadas por los inmigrantes a sus familias y allegados. En la reunión del G8, que se celebró en julio de 2009 en Aquila (Italia) los jefes de Estado y de Gobierno prometieron reducir el 50 por 100 los costos reales de las transferencias en el horizonte de 2013.

97 En este sentido, vid. Nussbaum, 2007: 229; GIBABERT, 2008: 430.

98 Sobre este aspecto, vid. LAPORTA, 2005: 232-235. 
los recursos» propuesto por POGGE, el impuesto redistributivo ideado en su momento por BARRY ${ }^{99}$, así como algunas de las más conocidas medidas redistributivas de la riqueza entre ricos y pobres defendidas en la arena internacional (la condonación de la deuda externa, la famosa tasa Tobin sobre los flujos de capitales, o la menos conocida «Brian Tax» o «renta básica global») serían propuestas de reforma del orden económico internacional que se situarían en esta línea redistributiva y solidaria.

\subsection{La concepción sistémica de la coacción}

Además de una extensión al plano global de la regulación de los intercambios globales que evite la erosión de la justicia de trasfondo, la construcción de una teoría de la justicia distributiva global podría descansar en una visión más amplia del tipo de coacción que, como vimos anteriormente, sirve de justificación para reducir el ámbito de la igualdad socioeconómica a las comunidades políticas estatales. Precisamente, una de las claves del giro que, con La pobreza en el mundo y los derechos humanos, POGGE imprime al cosmopolitismo reside en su insistencia en que existe un orden internacional, configurado por el FMI, la OMC, el Banco Mundial o el G-8, que daña a los menos aventajados, hasta el punto de imposibilitar la satisfacción de muchas necesidades básicas. Donde Pogge habla de daño, otros prefieren hablar de coacción. No nos referimos únicamente a aquellos ámbitos en los que, como ocurre con la Unión Europea o el Órgano de Solución de Controversias de la OMC, el derecho internacional ha alcanzado un grado de institucionalización muy próximo al de los ordenamientos nacionales. Pensemos también en otras prácticas más informales, como el modo en que el FMI supedita la concesión de préstamos a la reducción de las barreras al comercio y la democratización interna de unos países cuyas carencias hacen imposible, sin embargo, que puedan poner en marcha cualquier tipo de reforma; o los casos en los que la OMC impone sanciones comerciales a Estados que han adoptado algunas barreras comerciales no arancelarias, o la forma en que la Unión Europea y Estados Unidos subvencionan su propia producción agraria, forzando así a los agricultores de países en desarrollo a devaluar, en relación con sus propios costes de producción, el precio de sus productos para lograr hacerlos competitivos en el mercado. En todas estas situaciones resulta difícil negar que no se estén imponiendo normas de modo coactivo ${ }^{100}$.

Por tanto, aunque no deje de ser cierto que entre la coacción estatal e internacional existen diferencias importantes ${ }^{101}$, las mismas no tendrían la relevancia suficiente como para sustentar la tesis del estatismo sobre el alcance limitado de la justicia distributiva. Recordemos que, para NAGEL o BLAKE, sólo el tipo de fuerza «directa» sobre las personas basado en la amenaza de un mal, característico de lo que HART llama el modelo del asaltante ${ }^{102}$, exigiría una justificación respetuosa con el principio de la au-

9 BARRY, 1998: 159-160.

100 En un mundo donde cada vez existen más interconexión, resulta poco plausible seguir sosteniendo que el orden global no ejerce coacción COHEN y SABEL, 2006: 167-168.

101 Para un buen resumen de las mismas, vid. RISSE, 2006: 679-680.

102 Vid. HART, 1960: cap. II. El propio BLAKE se sirve de la comparación con el asaltante (gunman) para poner de manifiesto la especificidad de la coacción ejercida en el seno de los Estados frente a la existente en la esfera internacional. BLAKE, 2002: 277. 
tonomía personal. De acuerdo con esta concepción restringida, un agente A coacciona a otro B si intencionalmente lo fuerza a hacer, o abstenerse, de hacer algo mediante la amenaza de una sanción. Frente a esta visión paleopositivista, VALENTINI aboga por que consideremos la coacción un concepto «esencialmente controvertido», en el que cabría identificar un núcleo duro de significado, que señalaría lo moral y políticamente problemático de la coacción (la restricción de la autonomía), y distintas interpretaciones o concepciones de ese núcleo. De aceptar este nuevo enfoque, no habría razones para continuar limitando a las restricciones de la autonomía basadas en la amenaza de sanciones la justificación de la coacción en términos de justicia distributiva. La alternativa al modelo del asaltante podría encontrarse en la filosofía política kantiana, en la que la coacción es definida como un «impedimento a la libertad». Partiendo de esta idea, VALENTINI señala que, si la coacción pretende proporcionar una concepción plausible del objeto de la justicia, debería ser insensible al modo en que A restringe la libertad de B. No habría, pues, ninguna razón prima facie para que las restricciones de la libertad perpetradas mediante el uso de amenazas explícitas deban ser consideradas más problemáticas que las restricciones cometidas a través de otros medios. Partiendo de esta tesis, propone dos concepciones de la coacción superadoras de la estrechez del modelo del asaltante.

La primera es la que denomina concepción interacccional. Lo único que ésta requiere para hablar de coacción es: i) un agente responsable; ii) una restricción no trivial de la libertad de cualquier otro, y iii) una base para la comparación que permita evaluar si la libertad ha sido constreñida. Aquí la intencionalidad de la concepción restringida es sustituida por la condición más débil de la previsibilidad o evitabilidad. Lo que aquí se exige es que quienes coaccionan posean un grado razonable de control y previsión sobre las consecuencias en cuestión, pero no necesariamente que intenten producirlas.

Tanto la concepción restringida como la interaccional de la coacción asumen que quien coacciona es un agente moralmente responsable. Tanto en el ámbito doméstico como, de manera especial, en el internacional, ambas concepciones no servirían para captar algunas de las contriciones más relevantes en el plano de la justicia socioeconómica. Para dar cuenta de las mismas, VALENTINI introduce una nueva forma de entender de la coacción: la concepción sistémica. A diferencia de la interaccional, en la sistémica quien ejerce la coacción no es un agente identificable, ya sea un individuo o un grupo, sino un sistema de normas sociales, muchas veces opaco y difuso, apoyado por un número suficiente de agentes. De acuerdo con esta concepción, un sistema de normas S sería coactivo si, de forma previsible y evitable, impone constricciones no triviales a la libertad de algunos agentes, si la comparamos con la libertad de la que disfrutarían en ausencia de tal sistema ${ }^{103}$.

Un aspecto de la concepción sistémica que merece, si quiera brevemente, una particular atención es el tipo de responsabilidades que cabría asignar en un modelo en el que quien coacciona no es un agente sino un sistema de normas. ¿Cabe hablar de responsabilidades individuales o colectivas en tal caso? La respuesta sólo puede ser negativa si no se va más allá de los modelos estándar de responsabilidad jurídica y moral

103 VALENTINI, 2011: 213. 
(HONORÉ, FleTCHER), que supeditan la identificación y asignación de la responsabilidad a la existencia probada de una conexión causal entre la acción de un individuo o grupo de individuos claramente identificado/s y diferenciado/s y la restricción de la libertad (daño, coacción) sufrida por la víctima/s ${ }^{104}$. Las enormes dificultades que conlleva la aplicación de este modelo, concebido para situaciones de interacción face to face, a un contexto tan complejo como el de la pobreza global, en el que resulta imposible identificar conexiones causales directas entre las acciones u omisiones individuales y la producción del resultado, explicaría que la opinión más generalizada rechace que pueda hablarse de responsabilidades éticas individuales en relación con estos estados de $\operatorname{cosas}^{105}$.

Sin embargo, las transformaciones que ha traído consigo la globalización exigen respuestas diferentes a las tradicionales también en el plano de la responsabilidad ética y política. En el caso que nos ocupa, impone ensanchar esta noción hasta incluir en ella situaciones en las que no es posible dibujar con precisión el tipo de cadenas causales que producen un resultado, ni identificar claramente a quienes lo han provocado. Si queremos poner en consonancia nuestros conceptos éticos con el cambio de escala que impone un mundo globalizado, si queremos ser capaces de diseñar teorías normativas que den cuenta del modo en que las estructuras macrosociales determinan las perspectivas de vida de las personas, precisamos de una concepción más sofisticada de la agencia y de la responsabilidad. Tanto POGGE como Young han afrontado este reto concluyendo que, cuando el causante de la pobreza y otras grandes injusticias globales es un sistema de reglas y prácticas, las responsabilidades derivadas de sus efectos solo pueden ser indirectas: recaerían sobre aquellos que, ya sea apoyándolo o participando través de sus acciones y omisiones, se convierten en cómplices de dicho sistema ${ }^{106}$. Ambos comparten la convicción de que el modelo de responsabilidad reparativa que propugnan es más conforme con la intuición de que tenemos una deuda de justicia con los más desfavorecidos y, tanto más aún, que resulta mucho más persuasivo o retóricamente ventajoso que el defendido por SINGER ${ }^{107}$. Como es sabido, éste lleva décadas insistiendo en la conveniencia de desvincular en estos casos la responsabilidad derivada de la producción del resultado y unirla a la capacidad de ayudar fundamentada en el principio de que tenemos del evitar el mal, si ello no conlleva sacrificar nada moralmente comparable ${ }^{108}$.

POGGE señala que nuestras responsabilidades de ayuda hacia las víctimas de la pobreza global no brotarían de la inobservancia de unos deberes positivos de ayuda, sino de la violación del deber negativo de no dañar. Llega, incluso, a sugerir un fuerte paralelismo entre la responsabilidad del pueblo alemán por el holocausto judío y la que tendríamos los políticos y los ciudadanos de los países ricos respecto a la pobreza mundial. Sin embargo, termina concluyendo «que este paralelismo no persigue plantear cuestiones de responsabilidad o culpabilidad que dejo totalmente de lado, ni tampoco comparar nuestra conducta con la de los simpatizantes nazis» ${ }^{109}$. Su verdadero propó-

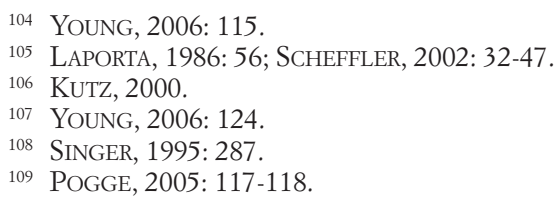


sito es apoyar una noción fuerte de responsabilidad derivada del resultado, que no se sustente en un vínculo causal entre éste y las acciones individuales sino en el apoyo de un conjunto amplísimo de personas a una estructura de normas y prácticas. Tal responsabilidad daría lugar a dos tipos de deberes reparativos: por un lado, el de rediseñar el orden internacional para que deje de provocar los efectos dañinos que actualmente genera y, por otro, el de compensar a los pobres mundiales por la privación que han sufrido hasta el momento.

Por su parte, I. YOUNG desarrolla bastante más las ideas de POGGE hasta ofrecer algunas claves con las que construir un modelo de responsabilidad para dar cuenta de las situaciones de coacción sistémica o injusticia estructural. La principal novedad aportada por YOUNG es que nuestra relación con las estructuras institucionales, políticas y sociales no es únicamente de apoyo o sostenimiento sino, por lo que respecta a las terceras, también de participación. El modelo — asevera YOUNG - sostiene que todos aquellos que participan con sus acciones en procesos que producen injusticia comparten la responsabilidad de remediarla ${ }^{110}$. En lo que aquélla llama modelo de responsabilidad basado en la conexión social (social connection model), y a diferencia del modelo tradicional basado en la causación de un daño (liability model), los individuos son responsables de la injusticia estructural, ya que contribuyen con sus acciones a los procesos que producen resultados injustos. Tal responsabilidad se deriva de formar parte, junto con otros, en un sistema de procesos interdependientes de cooperación y competencia, a través del cual se persiguen beneficios y llevan a cabo proyectos que producen injusticias estructurales. En el mundo actual — concluye YounG - muchos de estos procesos estructurales se extienden más allá de las fronteras del Estado-nación para abarcar a personas globalmente dispersas ${ }^{111}$.

\section{CONCLUSIONES}

A continuación, a modo de resumen, expondré las principales conclusiones que se desprenden de este trabajo:

1. El igualitarismo de la fortuna constituye uno de los pilares sobre el que han venido construyendo cosmopolitas como BEITZ, POGGE, BARRY y, más recientemente, CANEy, TAN, Mollendorf o BROWn, sus defensas de la regulación igualitaria de las desigualdades globales. Para todos ellos, el hecho de que las perspectivas de vida de las personas resulten determinadas, a veces casi por completo, por la lotería de haber nacido en un lugar del planeta y no en otro, resulta tan moralmente arbitrario que exige una compensación en términos de justicia y no sólo de beneficencia o humanidad. Más allá del atractivo, incluso apariencia de corrección, que parece ofrecer esta visión de la justicia como reparación del infortunio inmerecido, hemos podido analizar que el igualitarismo de la suerte, también en su versión global, sólo constituye una intuición o, en el mejor de los casos, un argumento para interesarnos por la situación de los menos aventajados del planeta, pero no una razón en favor de la igualdad (quizá sí de la

\footnotetext{
110 Young, 2006: 125.

111 Ibid., 119.
} 
humanidad) lo suficientemente fuerte y completa como para fundamentar, por sí sola, deberes de justicia distributiva.

2. La principal razón para cuestionar la suficiencia de las razones del igualitarismo de la suerte gira en torno al carácter conceptualmente institucional de la justicia. Este argumento ofrece, no obstante, versiones parcialmente diferentes en función, por un lado, del modo en que sean definidas las instituciones políticas y, por otro, del nivel de la teoría de la justicia en el que situemos esa conexión conceptual. El examen del contenido de cada una de ellas permite concluir que el IGS resulta rechazable por dos razones. En primer lugar, por la intuición manifestada por RAWLS de que la justicia no se aplica a los hechos, ya que estos son moralmente neutrales, sino al modo en que las instituciones actúan sobre ellos. En segundo lugar, la justicia tendría una naturaleza institucional debido a que la determinación de los criterios de cada reparto no puede llevarse a cabo fuera de un contexto político. Según esto, resultaría más correcto considerar a las instituciones (autoridades) como imprescindibles, no únicamente de cara la realización de la justicia, sino también al objeto de determinar, aunque sea parcialmente, sus contenidos.

3. Mucho más problemático se presenta el planteamiento de quienes, principalmente pero no solo de cara a desacreditar al IGS, elevan el carácter conceptualmente institucional de la justicia distributiva hasta el plano de la formulación de los primeros principios de ésta. Para quienes adoptan este enfoque, tal labor exigiría adoptar una actitud interpretativa compleja, capaz de percatarse de que, lejos de ser un ideal racional a la espera de encontrar instituciones que lo pongan en marcha, una justicia socioeconómica como la que se desprendería del principio de diferencia rawlsiano solo ha emergido como una demanda de igualdad sui generis, en el marco de las instituciones políticas ya existentes.

Debe reconocerse que esta concepción puede resultar adecuada para dar cuenta del modo en que, en el marco institucional en el que se desarrollan las relaciones entre conciudadanos, la intensidad y particularidad de la interactuación y las dependencias sociales pueden terminar reflejándose en los principios de justicia que las regulan. Sin embargo, una cosa es que para captar la especificidad del igualitarismo en las sociedades democráticas debamos admitir que el sentido de la regulación de las desigualdades económicas y sociales es asegurar que las relaciones entre conciudadanos esté presidida por la reciprocidad, y otra muy distinta que toda la justicia sea completamente dependiente de la práctica y no, en cierta medida, también ideal. Por tanto, sólo podemos aceptar una concepción de la justicia que incluya además y, sobre todo, por encima de este componente interpretativo de las prácticas existentes, valores independientes como la igualdad moral o la dignidad humana. La respuesta que deba darse al interrogante de si (una vez en que completan los deberes de justicia igualitaria respecto a los conciudadanos con unos deberes de beneficencia hacia todos los seres humanos) las concepciones estatistas de la justicia distributiva satisfacen o no este último requisito es, muy probablemente, el centro del debate entre liberales cosmopolitas y comunitaristas liberales.

4. En línea con algunas de las principales aportaciones realizadas en el plano de la teoría política de los últimos años, he tratado de mostrar las razones por las que un constructivismo que combine adecuadamente elementos dependientes e independien- 
tes de la práctica representa la alternativa más atractiva de cara a la elaboración de una teoría de la justicia distributiva global. Aquél, a diferencia del IGS, se situaría en un plano social e institucional y no sólo a priori e ideal. De esta forma, se preocuparía de identificar aquellas normas, pautas de interacción y estructuras de gobernanza con capacidad para influir decisivamente en las vidas de las personas, que les son aplicadas sin su consentimiento, y que poseen efectos sobre las posiciones socioeconómicas de los individuos, que habrían de ser consideradas objeto de la justicia a la luz de una lectura profunda de los valores que las sustentan. Por otro lado, este constructivismo sitúa el fundamento último de las exigencias más concretas de la justicia distributiva (como la regulación equitativa del comercio internacional o el acceso a los recursos naturales) en valores abstractos como el principio según el cual todos los individuos son auténticas fuentes de pretensiones válidas. Por último, permite evitar el riesgo del conservadurismo que encierran algunas formas de construir la justicia distributiva demasiado apegadas a las prácticas existentes. Con tal propósito, se ha examinado el papel que podrían jugar en la teoría de la justicia global una noción como la de «justicia de trasfondo» y las concepciones más amplias de la coacción o la responsabilidad, capaces de dar cuenta de las restricciones de la libertad que imponen las estructuras sociales y organizaciones supranacionales.

El examen de estas nociones permite concluir que, ni la coacción, ni seguramente cualquier otro hecho a partir del cual pretenda justificarse la especificad de las comunidades políticas estatales (cooperación, interdependencia, etc.) constituyen realidades o características exclusivas de éstas. También en las estructurales políticas internacionales es posible encontrar, aunque sea en menor medida o con una morfología parcialmente diferente, estos mismos hechos y prácticas. En consecuencia, frente al dualismo estatista y el monismo ético del IGS, una teoría de la justicia global que centre su atención en nociones como la de «justicia de trasfondo», o que suscriba una concepción amplia de la coacción, complicaría el cuadro de las responsabilidades éticas de carácter socioeconómico. En lugar de plantear la extensión de los principios de la justicia doméstica al plano global como una cuestión de todo (monismo) o nada (dualismo), prefería hablar de un continuum que abarcaría desde la justicia social doméstica, perfectamente cooperativa y articulada a través de una estructura básica, hasta el tipo de responsabilidad ética cuyo único fundamento sería la prioridad de la satisfacción de las necesidades más básicas y urgentes. Por el camino podría encontrar deberes menos exigentes que los de la justicia doméstica, pero que irían más allá de lo exigido por un principio de prioridad global. Así las cosas, mantener el dualismo justicia social y justicia global resulta cada vez más contraituitivo y poco atractivo. En el contexto internacional actual existe un amplio espectro de interacciones y relaciones de cooperación, así como formas cada vez más flexibles y diversas de membresía o ciudadanía, de las que brotarían para sus participantes responsabilidades que no llegarían al nivel de la justicia global igualitaria pero que irían, no obstante, más allá de lo estrictamente humanitario ${ }^{112}$. Así, por ejemplo, un individuo con nacionalidad o residencia en Francia tendría respecto a sus conciudadanos franceses deberes de justicia, basados en un esquema dirigido a

112 En esta línea COHEN y SABEL, 2005: 164. Cabría hablar, pues, de un espectro de grados de justicia igualitaria que deberíamos a los coparticipantes en esas estructuras colectivas, en proporción a nuestros grados de responsabilidad común y nuestra sujeción a la autoridad. TINNELVET y DE SCHUTTER, 2008: 535. 
la reducción de las desigualdades sociales y económicas, sustancialmente diferentes de los deberes de humanidad respecto a quienes sufren situaciones de necesidad o pobreza en cualquier lugar del planeta y, además, deberes más próximos a los primeros que a los segundos respecto a los ciudadanos del resto de países integrantes de la Unión Europea.

\section{REFERENCIAS}

AbizADEH, A., 2007: «Cooperation, Pervasive Impact, and Coercion: On the scope (not site) of Distributive Justice», Philosophy and Public Affairs, 35, 4, 319-358.

ANDERSON, E., 1999: «What is the Point of Equality?», Ethics, 109, 287-237.

ARCOS, F., 2009: La justicia más allá de las fronteras. Fundamentos y límites del cosmopolitismo, Valencia: Tirant Lo Blanch.

Aristóteles, 1997: Política, trad. de J. Marías y M. Araujo, Instituto de Estudios Políticos, 2. ${ }^{a}$ ed., Madrid.

ARneson, R., 2008: «Rawls, Responsibility and Distributive Justice», en M. SAlLeS y J. WeyMARK (eds.), Justice, Political Liberalism and Utilitarianism: Themes from Harsanyi, Cambridge Univ. Press, 80-107.

BARRY, B., 1991: «Humanity and Justice in global perspective», Liberty and Justice: Essays in Political Theory, Oxford: Clarendon Press, 182-210.

- 1998: «International Society from a Cosmopolitan Perspective», en D. MAPEL y T. NARDIN (eds.), International Society and Etbics, Princeton, 144-163.

BeITZ, C., 1979: Political Theory and International relations, New Jersey: Princeton University Press.

- 1999: «Social and Cosmopolitan Liberalism», International Affairs, 75, 3, 515-529.

BenHABIB, S., 2005: Los derechos de los otros. Extranjeros, residentes y ciudadanos, trad. de G. Zadunaisky, Barcelona: Gedisa.

Bertram, C., 2006: «Cosmopolitan and equality», Res Publica, 12, 327-336.

Blake, M., 2002: «Distributive justice, State Coercion, and Autonomy», Philosophy and Public Affairs, 30, núm. 3, 257-296.

Brown, A., 2008: «Are There Any Global Egalitarian Rights?», Human Rights Review, vol. 9, 435-464.

- 2009: Ronald Dworkin's Theory of Equality. Domestic and Global Perspectives, London: Palgrave MacMillan.

Caney, S., 2001: «Cosmopolitan Justice and Equalizing Opportunities», en T. Pogge (ed.), Global Justice, Oxford: Blackwell, 123-144.

- 2002: «Survey Article: Cosmopolitanism and The Law of Peoples», The Journal of Political Philosophy, 10, 1, 95-123.

CARENS, J., 2009: «Extranjeros y ciudadanos. Un argumento a favor de las fronteras abiertas», Isonomía. Revista de Teoría y Filosofía del Derecho, 30, 53-80.

CAVALLAR, G., 1999: Kant and the theory and practice of international right, Cardiff: University of Wale Press.

DANIELS, N., 2003: «Democratic Equality: Rawl's Complex Egalitarianism», en S. FreEMAN (ed.), The Cambridge Companion to Rawls, Cambridge University Press, 241-276.

De LuCAS, J., 2002: «La herida original de las políticas de inmigración. A propósito del lugar de los derechos humanos en las políticas de inmigración», Isegoría, núm. 26, 59-84. 
DwORKIN, R., 1995: A matter of principles, Massachusetts: Harvard University Press.

- 2003: Virtud soberana. La teoría y la práctica de la igualdad, trad. de F. Aguiar y M. J. Bertomeu, Barcelona: Paidós.

FABRE, C., 2005: «Global Distributive Justice: An Egalitarian Perspective», Canadian Journal of Philosophy (volumen suplementario), 139-164.

FrAzER, N., 2005: «Redefiniendo el concepto de justicia en un mundo globalizado», Anales de la Cátedra Francisco Suárez, 67-84.

- 2008: Escalas de Justicia, trad. de A. Martínez Riu, Barcelona: Herder.

FreEman, S., 2006: «The Law of Peoples, Social Cooperation, Human Rights and Distributive Justice», Social Philosophy E Policy, núm. 23, 29-68.

Gilabet, P., 2008: «Global Justice and Poverty Relief in Non ideal Circumstances», Social Theory and Practice, 34, 3, 411-438.

Goodin, R.; Pettit, P., y Pogge, T. (eds.), 2007: A Companion to contemporary political philosophy, Malden, M. A.: Blackwell.

Habermas, J., 2010: «El concepto de dignidad humana y la utopía realista de los derechos humanos», Dianioa, vol. LV, 64, 3-25.

HaHN, H., 2009: «The global consequence of participatory responsibility», Journal of Global Ethics, 5, 1, 43-56.

Hart, H. L. A., 1960: El concepto de derecho, trad. de G. Carrió, Buenos Aires: Abeledo-Perrot.

Heymann, S., 1992: «Aristotle on Political Justice», Iowa Law Review, 77, 851-863.

Hierro, L., 2002: «El concepto de justicia y la teoría de los derechos», en E. DíAZ y J. L. ColOMER (eds.), Estado, justicia, derechos, Madrid: Alianza Editorial, 11-73.

- 2009: «Justicia Global y Justicia Legal. ¿Tenemos derecho a un mundo justo?», Doxa. Cuadernos Filosofía del Derecho, 32, 341-374.

Hobbes, T., 1971: Leviatán, trad. de C. Moya y A. Escohotado, Madrid: Editora Nacional.

Holtug, N., 2009: «Equality, Priority and Global Justice», Journal of Global Ethics, 5, 3, 173-179.

Hurley, S., 2001: «Luck \& Equality», Proceedings of the Aristotelian Society, volúmen suplementario LXXV, 51-72.

IGLESIAS, M., 2005: «Justicia Global y Derechos Humanos: Hacia una ética de las prioridades», Anuario de la Facultad de Derecho de la Universidad Autónoma de Madrid, 9, 41-70.

— 2006: «El desafío moral de la pobreza: Deberes individuales y estándares de humanidad», en A. García Figueroa, Racionalidad y derecho, Centro de Estudios Políticos y Constitucionales.

James, A., 2005: «Constructing Justice for Existing Practice: Rawls and the Status Quo», Philosophy \& Public Affairs, 33, 3, 281-316.

Juluis, P., 2006: «Nagel's Atlas», Philosophy and Public Affairs, 34, 2, 176-192.

Kutz, C., 2000: Complicity: Ethics and Law for a Collective Age, New York: Cambridge University Press.

KymlicKA, W., 1995: Filosofía política: una introducción, trad. de R. Gargarella, Barcelona: Ariel.

LAPORTA, F., 1986: «Algunos problemas de los deberes positivos generales», Doxa, 3, 55-63.

— 2005: «Globalización e imperio de la ley. Un texto provisional para el debate con algunas dudas y perplejidades de un viejo westfaliano», Anales de la Cátedra Francisco Suárez, 231-252.

MARTí, J. L., 2006: La república deliberativa: una teoría de la democracia, Madrid: Marcial Pons.

MECKLED-GARCIA, S., 2008: «On the very Idea of Cosmopolitan Justice: Constructivism an International Agency», The Journal of Political Philosophy, 16, 2, 245-271. 
Miller, D., 2007: National Responsibility and Global Justice, Oxford: Oxford University Press. - 2008: «A response», Critical Review of International Social and Political Philosophy, 11, 4, 553-567.

NAGEL, T., 2005: «The problem of global justice», Philosophy \& Public Affairs, 33, 2, 113-147.

Nussbaum, M. (ed.), 1999: Los límites del patriotismo. Identidad, pertenencia y ciudadanía mundial, trad. de Carme Castells, Barcelona: Paidós, 13-29.

- 2006: Las fronteras de la justicia. Consideraciones sobre la exclusión, trad. de R. Vila y A. Santos, Barcelona: Paidós.

Pérez ReY, J. L., 2011: «Qué tipo de impuestos exige la renta básica», en M. E. RodríGuez PALOP, J. L. REY PÉREZ e I. CAMPOY CERVERA (eds.), Desafíos actuales a los derechos humanos: la renta básica y el futuro del Estado social, Madrid: Dykinson, en prensa.

Pevnick, R., 2008: «Political Coercion and The Scope of Distributive Justice», Political Studies, 56, 399-413.

POGGE, T., 2004: «La incoherencia entre la teoría de la justicia de Rawls», trad. de D. Álvarez, Revista Internacional de Filosofía Política, 23, 28-48.

- 2006: La pobreza en el mundo y los derechos humanos, trad. de E. Weikert, Barcelona: Paidós.

Rawls, J., 1978: Teoría de la justicia, trad. de M. D. González, Fondo de Cultura Económica.

- 2001: El derecho de gentes y «una revisión de la idea de razón pública», trad. de F. Valencia, Barcelona: Paidós.

- 2002: Justicia como equidad. Una reformulación, trad. de A. de Francisco, Barcelona: Paidós.

RibOtTA, S., 2009: Las desigualdades económicas en la teoría de la justicia. Pobreza, redistribución y justicia social, Madrid: Centro de Estudios Políticos y Constitucionales.

Risse, M., 2006: «What to Say about the State?», Social Theory E Practice, 34, 2, 671-698.

RonZONI, M., 2009: «The Global Order: A Case of Background Injustice? A Practice-Dependet Account», Pbilosophy \& Public Affairs, 37, 3, 230-255.

RUMMERS, S., 2009: «No Justice without democracy. A deliberative approach to the global distribution of wealth», International Journal of Philosophical Studies, vol. 17, núm. 5, 657-680.

Sangiovanni, A., 2008: «Justice \& the Priority of Politics to Morality», The Journal of Political Philosophy, 16, 2, 134-167.

SASSEN, S., 2001: ¿Perdiendo el control? La soberania en la era de la globalización, Barcelona: Bellaterra.

SCHEFFLER, S., 2001: Boundaries and Allegiances. Problems of Justice and Responsibility in liberal thought, Oxford University Press.

- 2003: «What is Egalitarianism?», Philosophy \& Public Affairs, 31, 1, 5-39.

- 2008: «Cosmopolitanism, justice \& institutions», Daedalus, Summer, 137, 3, 68-77.

SCHEmmel, C., 2007. «On the Usefulness of Luck Egalitarian Arguments for Global Justice», Global Justice: Theory Practice Rhetoric, 1, 54-67.

Sen, A., 2010: La idea de la justicia, trad. de H. Valencia Villa, Madrid: Taurus.

Singer, P., 1995: «Ricos y pobres», en Ética Práctica, 2. ${ }^{a}$ ed., trad. de R. Herrera Bonet, Cambridge University Press, 271-307.

- 2003: Un solo mundo. La ética de la globalización, trad. de F. Herreros, Barcelona: Paidós.

TAN, K. C., 2004: Justice without borders: Cosmopolitanism, nationalism and patriotism, Cambridge University Press.

- 2008: «A defense of luck-egalitarianism», The Journal of Philosophy, CV, 11, 665-690.

Tinnelvet, R., y DE SchuTter, H., 2008: «Global justice for a world of largely independent nations? From dualism to a multi-level ethical positions», Critical Review of International Social and Political Pbilosophy, 11, 4, 519-538. 
TurÉGANO, I., 2010: Justicia global. Los límites del constitucionalismo, Lima: Palestra.

Valentini, L., 2010: «Global Justice and Practice-Dependence: Conventionalism, Institutionalism, Functionalism», The Journal of Political Philosophy, 19, 4, 1-20.

- 2011: «Coercion and (Global) Justice», American Political Science Review, 105, 1, 205-220.

VAn Parijs, P., 2007: «International distributive justice», en R. E. GoOdin, P. Pettit y T. Pogge (eds.), A Companion to Contemporary Political Philosophy, Oxford: Blackwell, 638-652.

VelasCO, J. C., 2010: «La justicia en un mundo globalizado», Isegoría, 43, 349-362.

Young, I. M., 2002: Más allá de las fronteras, traducción de R. M. Mejía y Veronica Lifrieri, Buenos Aires: Milo y Dávila.

- 2006: «Responsibility and Global Justice: a social connection model», Social Philosophy E Policy, 23, 1, 102-130.

YPI, L., 2009: «On the confusion between Ideal and Non-ideal in Recent debates on Global justice», Political Studies, 58, 1-19.

- 2010: «Justice and Morality beyond naïve cosmopolitanism», Ethics E Global Politics, 3,2, 171-192. 